\title{
POLYMERIC BIOMATERIALS AND NANOMEDICINES
}

\section{Jiyuan Yang ${ }^{1}$, Jindřich Kopeček ${ }^{1,2, \star}$}

${ }^{1}$ Department of Pharmaceutics and Pharmaceutical Chemistry, ${ }^{2}$ Department of Bioengineering, University of Utah, Salt Lake City, Utah 84112, USA

*Corresponding author: Jindřich Kopeček, Center for Controlled Chemical Delivery, $20 \mathrm{~S}$ 2030 E, BPRB 205B, University of Utah, Salt Lake City, UT 84112-9452, USA.

Phone: (801) 581-7211; Fax: (801) 581-7848.

E-mail address: jindrich.kopecek@utah.edu (J. Kopeček) 


\begin{abstract}
This overview intends to demonstrate the close relationship between the design of smart biomaterials and water-soluble polymer-drug conjugates. First, the discovery and systematic studies of hydrogels based on crosslinked poly(meth)acrylic acid esters and substituted amides is described. Then, the lessons learned for the design of watersoluble polymers as drug carriers are highlighted. The current state-of-the-art in watersoluble, mainly poly[N-(2-hydroxypropyl)methacylamide (HPMA), polymer-drug conjugates is shown including the design of backbone degradable HPMA copolymer carriers. In the second part, the modern design of hybrid hydrogels focuses on the selfassembly of hybrid copolymers composed from the synthetic part (backbone) and biorecognizable grafts (coiled-coil forming peptides or morpholino oligonucleotides) is shown. The research of self-assembling hydrogels inspired the invention and design of drug-free macromolecular therapeutics - a new paradigm in drug delivery where crosslinking of non-internalizating CD20 receptors results in apoptosis in vitro and in vivo. The latter is mediated by biorecognition of complementary motifs; no low molecular weight drug is needed.
\end{abstract}

\title{
Keywords:
}

Hydrogels

Nanomedicines

Cancer

Polymer-drug conjugates

Self-assembly of macromolecules

Drug-free macromolecular therapeutics 


\section{Introduction}

In this overview we intend to demonstrate the close relationship between the design of biomaterials and the design of nanomedicines as experienced in our research. One of us (JK) was a graduate student at a laboratory where hydrogels, the first rationally designed biomedical polymers, were discovered by Drahoslav Lím [1,2] and soft contact lenses designed by $\mathrm{O}$. Wichterle [3] in the 1950s. These discoveries initiated biomaterial and nanomedicine research worldwide and for many remain an inspiration today.

Original hydrogels were synthesized by traditional radical copolymerization of vinyl and divinyl (crosslinker) compounds. The first hydrogels were based on hydrophilic esters of methacrylic acid - e.g. the first soft contact lenses were a copolymer of 2-hydroxyethyl methacrylate (HEMA) with ethylene dimethacrylate (EDMA). Numerous hydrogel struktures followed [2] and a detailed study of the relationship between the composition of hydrogels and their biocompatibility [4] was the driving force for the design of watersoluble polymeric carriers based on $\mathrm{N}$-substituted methacylamides and development of polymer-drug conjugates, one of the most promising nanomedicines.

Our recent hydrogel research focuses on the self-assembly of hydrogels from hybrid block or graft copolymers driven by the interaction of complementary biorecognition motifs [5]. Both peptide/protein [6,7] and oligonucleotide [8] motifs have been used in hydrogel design. For example, two distinct pentaheptad peptides (CCE and CCK) were designed to create a dimerization motif and serve as physical crosslinkers. Indeed, graft copolymers, P-CCE and P-CCK (P is the $N$-(2-hydroxypropyl)methacylamide (HPMA) backbone), self-assembled into hybrid hydrogels. The hydrogel formation was mediated by the formation of antiparallel coiled-coil CCK/CCE heterodimers $[6,9]$. This research was the motivation for the design of "drug-free macromolecular therapeutics" [10]. Formation of coiled-coil heterodimers at B-cell surface resulted in the crosslinking of CD20 (non-internalizating) receptors and initiation of apoptosis [10,11].

The above two examples indicate the close relationship between biomaterials research and the design of nanomedicines. In this report we shall try to make this connection more clear.

\section{Traditional hydrogels and water-soluble polymeric drug carriers}

\subsection{Discovery, early research and clinical applications of hydrogels}

Hydrogels were systemically studied by Lím and Wichterle in the 1950s in Prague. They have chosen methacroylated derivatives because the structure of the polymer reflects a pivalic (trimethylacetic) acid structure. The latter is stable to pure hydrolysis and no similar structure in the nature was known, making enzyme-catalyzed hydrolysis less probable [12]. After trying the methacroylated polyvinyl alcohol and partially substituted mannit [13], Lim hit the jackpot when he left the transesterification of methyl methacrylate with triethylene glycol overnight in the middle of the work-up; he added water to separate the triethylene glycol dimethacrylate layer from water soluble components. However, during night the water layer turned into a clear hydrogel. Obviously it was a copolymer of triethylene glycol monomethacrylate and triethylene glycol dimethacrylate [12]. A detailed evaluation of similar crosslinked copolymers from monoglycol and diglycol led to the selection of monoglycol (copolymer of HEMA and EDMA) for the synthesis of first soft contact lenses $[1,14]$. 
Paralell with the development of soft contact lenses other medical applications commenced - glaucoma microcapillary drains [15], augmentation of vocal cords [16], restoration of detached retina [17], preventing scar formation after surgery [18], and covering for perforated ear drums [19]. There are numerous excellent reviews that describe the early work on hydrogels [2,14,20-24].

\subsubsection{Structure - biocompatibility relationship}

Healing-in of hydrogel implants depends on the chemical structure, physical structure (porosity), and surface microarchitecture of hydrogels [25]. A systematic study of the biocompatibility of hydrogels based on esters and/or $N$-substituted amides of (meth)acrylic acid revealed no significant differences in the healing-in of hydrogels of different chemical compositions [4,26-29]. In contrast, significant differences have been observed for hydrogels with different porosity [30,31].

Hydrogels prepared by crosslinking copolymerization of HEMA with EDMA are an excellent model for the study of the relationship between porosity and biocompatibility. Due to the fact, that the interaction parameter $(\chi)$ polymer-water for this system is 0.70.8 (depending on crosslinking density) [32], phase separation may occur during copolymerization, which depends on the amount of water in the feed. Manipulating the water to monomer ratio in the feed permits the formation of homogeneous (transparent) hydrogels $(<50 \%$ water in the feed), microporous hydrogels (pores are not interconnected; $50-70 \%$ water in the feed), and macroporous spongy hydrogels with interconnecting channels ( $>70 \%$ water in the feed) [31]. Thus, the biocompatibility of hydrogels with identical chemical structure, but differing in porosity could be evaluated $[30,31]$. The implantation of both homogeneous and heterogeneous hydrogels resulted in fibrous capsule formation. However, following implantation of porous hydrogels, in contrast to homogeneous hydrogels, newly formed blood capillaries and an eosinophil containing exudate penetrated into the implant. The intensity and the area of penetration were greater with higher hydrogel porosity [30,31]. An investigation of calcium deposits using von Kóssa staining revealed the dependence of the extent and localization of calcium deposits on porosity. There was only sporadic calcification in the margin of the implant following implantation of homogeneous or microporous hydrogels; however, with an increase in porosity, calcification occurred. The site of the deposition moved from the margin of the implant toward its center with increasing porosity [31]. Early studies on the biocompatibility of hydrogels have been summarized in ref. [4].

These results were corroborated in clinical settings. Implantation of homogeneous HEMA-based hydrogels to treat nasal malformation resulted in minor calcification at the margin of the implant (about 50\% of patients evaluated after 3-10 years). Apparently, with scalpel damaged surface (due to surgeons modifying the size of the hydrogel implants in the operation room) connective tissue accumulated and initiated calcium deposition. Minor calcium deposition did not affect the biocompatibility or the final cosmetic effect (Fig. 1) [33,34].

Figure 1

\subsubsection{Stimuli-sensitive hydrogels}


Stimuli- sensitive polymers exhibit sharp changes in behavior in response to an external stimulus, such as pH, temperature, solvents, salts, electrical field, and chemical or biochemical agents. Such polymers may be used in numerous applications, including phase separations, affinity precipitations, bioactive surfaces, permeation switches, bioreactors, medical diagnostics, and drug delivery systems [35].

Upon a change in the environment, hydrogels swell or collapse. Environmentally induced changes in the transport properties of $\mathrm{pH}$-sensitive hydrogels [36,37] or temperature-sensitive hydrogels [38] were studied several decades ago. Dušek and Paterson [39] predicted that changes in external conditions might result in abrupt changes of the hydrogel degree of swelling (phase transition). Tanaka et al. [40] and others $[41,42]$ have verified the theory by experimental observations.

The majority of temperature-sensitive polymer hydrogels have a LCST, i.e., the gels collapse as the temperature increases. The process is thought being driven by entropy, which is supported by the observation that LCST transitions are endothermic. One widely accepted mechanism is based on disruption and re-establishment of a balance between hydrophobic and electrostatic interactions. Below the LCST, water molecules form hydrogen bonds with polar groups on the polymer backbone and organize around hydrophobic groups as iceberg water. As temperature increases past LCST, bound water molecules are released to the bulk with a large gain in entropy, resulting in the collapse of the polymer network [43].

Incorporation of enzyme-degradable peptide sequences [44] as crosslinks renders the hydrogels enzymatically degradable. Interestingly, the degree of swelling decides if the degradation occurs from surface or is bulk degradation. In the latter case the swelling degree has to be high so that the enzyme can diffuse into the hydrogel structure [45].

\subsection{Lessons learned from hydrogel research suitable for the design of water-soluble polymers as drug carriers}

We studied the structure-properties relationship of hydrophilic esters and $N$-substituted amides of (meth)acrylic acid. While hydrophilic esters of methacrylic acid (monoesters of glycol [32], diglycol [46,47] and triglycol [48]) produced crosslinked polymers (hydrogels) with excellent properties from the application point of view, the $N$-substituted amides represented a group of polymers where properties could be easily manipulated by choosing the proper substituent on the amide nitrogen [4,49]. Hydrophilic esters (prepared by transesterification) always contained a small (variable) amount of diester as an impurity. This was not a problem for the synthesis of hydrogels, but prevented the synthesis of soluble polymers with reproducible molecular weight distribution. Thus the experience from hydrogels directed us to concentrate on $N$-substituted amides of (meth)acrylic acid in the design of soluble polymeric drug carriers. Based on the detailed studies of the relationship between the structure of hydrophilic polymers and their biocompatibility [4,26-29], we have chosen $N$-substituted methacrylamides as our target because the $\alpha$-carbon substitution and the $N$-substituted amide bond ensured hydrolytic stability of the side-chains. We synthesized a series of compounds trying to identify a crystalline monomer for easy purification and reproducible synthesis. The first crystalline $\mathrm{N}$-substituted methacrylamide we succeeded to synthesize, $\mathrm{N}$-(2hydroxypropyl)methacrylamide (HPMA), was chosen for future development. This ensured a reproducible synthesis of water-soluble polymeric carriers [55-57]. 


\subsection{Advances in soluble polymer-drug conjugates}

The validation of polyHPMA $[55,56]$ as a drug carrier was based on evaluation of its biocompatibility using all test required for blood plasma expanders [50-54,58]. The development of HPMA copolymer - drug conjugates was based on basic biological principles that govern the behavior of macromolecules.

The major rationale for the use of water-soluble polymers as carriers of anticancer drugs is based on the mechanism of cell entry [54,58,59]. Whereas the majority of low molecular weight drugs enter the cell by diffusion across the plasma membrane, the entry of macromolecules is restricted to endocytosis [60,61]. Macromolecules captured by this mechanism are usually channeled to the lysosomal compartment of the cell. Moieties incorporated into the macromolecular structure that complement cell surface receptors or antigens of a subset of cells, render the macromolecule biorecognizable $[62,63]$. For efficiency, targetable polymer - drug conjugates should be biorecognizable at two levels: at the plasma membrane, eliciting selective recognition and internalization by a subset of target cells $[62,64]$, and intracellularly, where lysosomal enzymes induce the release of drug from the carrier [65]. The latter is a prerequisite for transport of the drug across the lysosomal membrane into the cytoplasm and translocation into the organelle decisive for biological activity.

There are numerous reviews that summarize the rationale, design, synthesis, and evaluation of macromolecular therapeutics [44,58,59,66-77]. Here, we shall discuss just four important topics in water-soluble nanomedicines: combination therapy, multidrug resistance, backbone degradable polymer carriers, and importance of targeting.

\subsubsection{Combination therapy}

Photodynamic therapy is a paradigm in anticancer therapy that involves activation of specific compounds, called photosensitizers. Illumination of these compounds results in the generation of free radicals and singlet oxygen, which cause cell damage and ultimately cell death. A combination of chemotherapy and photodynamic therapy may result in a synergistic response, resulting in a better cure rate than monotherapy. On two cancer models, Neuro 2A neuroblastoma [78] and human ovarian carcinoma heterotransplanted in the nude mice [79], we have shown that combination therapy with HPMA copolymer - anticancer drug [DOX and meso chlorin $\mathrm{e}_{6}$ mono( $\mathrm{N}-2$ aminoethylamide) $\left\{\mathrm{Mce}_{6}\right\}$ ] conjugates showed tumor cures that could not be obtained with either chemotherapy or photodynamic therapy alone. Cooperativity of the action of both drugs contributed to the observed effect [80]. Based on biodistribution data [81], we hypothesized that combination therapies of S.c. human ovarian carcinoma OVCAR-3 xenografts in nude mice using multiple doses/irradiation of $P(G F L G)-M_{c e}$ ( $P$ is the HPMA copolymer backbone) and P(GFLG)-DOX may acquire low effective doses without sacrificing the therapeutic efficacy. Indeed, 10 out of 12 tumors exhibited complete responses in the group of mice receiving multiple PDT plus multiple chemotherapy [82].

Employing targeted combination chemotherapy and photodynamic therapy using OVTL16-targeted HPMA copolymer-DOX and HPMA copolymer-mesochlorin $\mathrm{e}_{6}$ conjugates results in enhanced tumor accumulation and treatment efficacy. OV-TL16 antibodies are complementary to the OA-3 antigen (CD47) present on the majority of ovarian cancers. 
The immunoconjugates (Figure 3) preferentially accumulated in human ovarian carcinoma OVCAR-3 xenografts in nude mice with a concomitant increase in therapeutic efficacy when compared with non-targeted conjugates [64]. The targeted conjugates suppressed tumor growth for the entire length of the experiment ( $>60$ days).

Other combination systems were quantitatively evaluated by combination index $(\mathrm{Cl})$ analysis in A498 renal carcinoma cells [83] and in OVCAR-3 ovarian carcinoma cells [84]. The results demonstrated synergistic effects of HPMA copolymer-drug (SOS thiophene, DOX, and chlorin $e_{6}$ ) conjugate combinations in a wide range of concentrations. Recently, the regions of synergism for the combination of backbone degradable HPMA copolymer-gemcitabine and HPMA copolymer-paclitaxel conjugates [85] and backbone degradable HPMA copolymer-gemcitabine and HPMA copolymerplatinum conjugates [86] have been identified.

A detailed comparison of the efficacy of combination therapy of ovarian carcinoma with $1^{\text {st }}$ and $2^{\text {nd }}$ generation HPMA copolymer - PTX and GEM conjugates clearly demonstrated the advantage of long circulating $2^{\text {nd }}$ generation conjugates - favorable pharmacokinetics, dramatically enhanced inhibition efficacy on tumor growth, and absence of adverse effects [87]. The second generation of backbone degradable HPMA copolymer carriers is discussed below.

From the synthetic and scale-up point of view it is preferable to use a mixture of two polymer-conjugates, each containing one drug. However, Vicent et al. have shown that for some drug combinations binding two drugs to the same macromolecule results in higher efficacy when compared to a mixture of two polymer drugs [88]. Recently, a new therapeutic strategy for bone neoplasms using combined targeted polymer-bound angiogenesis inhibitors (two per macromolecule: ALN and antiangiogenic TNP-470) was developed. The bi-specific HPMA copolymer-ALN-TNP-470 is the first antiangiogenic conjugate that targets both the tumor epithelial and endothelial compartments, warranting its use on angiogenesis-dependent calcified neoplasms such as osteosarcomas and bone metastases $[89,90]$.

\subsubsection{Targeting stem cells}

Another important aspect for the future development of anticancer nanomedicines is the targeting of cancer stem cells [66,73,91,92]. Cancer cells are biologically and functionally heterogeneous, in terms of phenotype, proliferation, tumorigenesis and invasiveness, etc. Noticeably, cancer cells are present in various differentiation statuses, with relatively undifferentiated Cancer Stem Cells (CSCs) maintaining the hierarchical organization of the tumor mass, similar to the role of normal stem cells (NSCs) in healthy tissues $[93,94]$. Moreover, the CSC theory suggests that the often-observed treatment failures are largely due to the failure of conventional cytotoxic anti-cancer therapies to eliminate CSCs. Therefore, targeting CSCs or in combination with traditional anticancer therapeutics represents a promising strategy to improve cancer patient survival [95]. Aiming to improve the outcome of prostate cancer treatments by targeting CSCs, we designed a CSC specific nanomedicine. Cyclopamine, a hedgehog pathway inhibitor, was attached to the end of GFLG (glycylphenylalanylleucylglycyl) biodegradable tetrapeptide side chains of HPMA copolymer. We evaluated the CSC inhibitory effects of the HPMA copolymer-cyclopamine conjugate in an in vitro prostate cancer epithelial cell model, RC-92a/hTERT cells, with stem cell properties [96]. RC-92a/hTERT cells were chosen since the CD133+/integrin $\alpha 2 \beta 1^{\text {hi }} / C D 44+$ putative prostate CSCs within the 
whole cell line could be enriched to $5 \%$, higher than that reported on primary prostate cancer cells or other established prostate cancer cell lines. Cell surface marker expression analysis and cytotoxicity studies following drug and conjugate treatments on RC-92a/hTERT cells supported the anti-CSC efficacy of the designed macromolecular therapeutics. The HPMA copolymer-cyclopamine conjugate, like free cyclopamine, showed selective inhibitory effect on prostate CSCs than on bulk cancer cells in the in vitro prostate cancer model. In contrast, docetaxel, a traditional chemotherapeutic agent for prostate cancer, showed preferential cytotoxicity to bulk cancer cells. These results suggest the treatment potential of a combination macromolecular therapeutics targeting both bulk tumor cells and CSCs [91].

We also evaluated the in vivo tumor growth inhibitory effect in long-term. The combination of P-CYP (HPMA copolymer-cyclopamine conjugate) and P-DTX (HPMA copolymer-docetaxel conjugate), as well as the P-CYP or P-DTX single treatment all inhibited the PC-3 prostate tumor growth to certain extent compared to saline group, immediately after three-week treatment (Fig. 2) [92]. However, after stopping the treatment at day 21 only the combination of P-CYP and P-DTX showed persistent tumor growth inhibition, leading to the longest mice survival on average (Fig. 4A) [92,97].

Figure 2

\subsubsection{Overcoming multidrug resistance}

The acquired resistance of malignant tumors to therapeutics is one of the major causes of cancer therapy failure [98]. Membrane transporters from the ATP-Binding Casette $(A B C)$ transport proteins families (P-glycoprotein, multidrug resistance-associated proteins and others) reduce the intracellular drug concentration. The elucidation of the function of P-glycoprotein [99], other ATP-driven efflux pumps [100], as well as other mechanisms of multidrug resistance [101] have had a major impact on the understanding of multidrug resistance in human tumors. The exclusion of nanomedicines, including polymer-drug conjugates, from the cytoplasm of the cell, through intracellular trafficking in membrane-limited organelles, renders the efflux pumps less efficient [102]. Subcellular trafficking along the endocytic pathway from the plasma membrane to the perinuclear region changes the gradient of distribution of drugs inside cells [103-105]. The concentration gradient of free drugs is directed from the plasma membrane to the perinuclear region (in the direction of diffusion); conversely, in polymer-bound drugs, the drug is released from the carrier in the lysosomal compartment located in the perinuclear region, have a concentration gradient in the opposite direction. Consequently, the interaction/recognition of the released drug by the P-glycoprotein efflux pump is minimized [104]. Quantitative determination of intracellular DOX concentration following exposure of human ovarian carcinoma cells to free and HPMA copolymer-bound DOX showed an enhanced intracellular accumulation of HPMA copolymer-bound DOX [106]. Efficient bypassing of multidrug resistance was detected for other drug delivery systems internalized by endocytosis, namely lipid/polymer particle assemblies, dendrimers, and micelles [102].

\subsubsection{Backbone degradable long circulating conjugates}

It is well known that high molecular weight (long-circulating) polymer conjugates accumulate efficiently in solid tumor tissue due to the EPR (enhanced permeability and retention) effect $[71,72,107]$. To achieve substantial accumulation of the polymer-drug conjugate in solid tumors (due to the EPR effect) a sustained concentration gradient is 
needed. The concentration in the blood stream depends on the administered dose and on the molecular weight of the carrier. However, higher molecular weight drug carriers with a nondegradable backbone deposit and accumulate in various organs, impairing biocompatibility.

Previous attempts to design and synthesize long-circulating conjugates produced branched, partially crosslinked copolymers with enzymatically degradable sequences [108]. The synthetic process and the polymer structure were difficult to control; consequently, the process would be difficult to scale-up. Nevertheless, the results proved that a higher molecular weight of polymer carriers transfers into higher accumulation of drugs in the tumor tissue with concomitant enhancement of efficacy [109].

The advances in controlled radical polymerization $[110,111]$ and click chemistry [112114] offered new vistas for the design and synthesis of long-circulating biocompatible polymer-drug conjugates. To this end we designed new, second-generation anticancer nanomedicines based on high molecular weight HPMA copolymer carriers containing enzymatically degradable bonds in the main chain (polymer backbone) [115117]. The proposed new design permits tailor-made synthesis of well-defined backbone degradable HPMA copolymers. The synthetic process consists of two main steps: first, the synthesis of a telechelic HPMA copolymer by reversible addition-fragmentation chain transfer (RAFT) polymerization, followed in the second step by chain extension using alkyne-azide $[115,116]$ or thiol-ene [117] click reactions. In addition, we synthesized a new RAFT chain transfer agent (CTA), $\quad N^{\alpha}, N^{\varepsilon}$-bis(4-cyano-4(phenylcarbonothioylthio)pentanoylglycylphenylalanylleucylglycyl) lysine (Peptide2CTA), containing an enzymatically degradable (GFLG) spacer capped at both ends with 4cyano-4-(phenylcarbonothioylthio)pentanoate [117]. During RAFT polymerization the HPMA monomers incorporate at both dithiobenzoate groups of the Peptide2CTA with identical efficiency. When the final polymer was incubated with papain, a thiol proteinase with similar specificity as lysosomal proteinases, the molecular weight decreased to half of the original value. Thus it is possible to prepare a degradable diblock copolymer with narrow molecular weight distribution in one step, eliminating the chain extension reaction [117].

Multiblock polyHPMAs with Mw as high as $300 \mathrm{kDa}$ and containing degradable GFLG sequences were obtained by chain extension followed by fractionation using size exclusion chromatography (SEC). The exposure of the multiblock HPMA copolymer to model enzyme papain or lysosomal cathepsin $\mathrm{B}\left(\mathrm{pH} 6,37^{\circ} \mathrm{C}\right)$ resulted in complete degradation of GFLG segments and decrease of the molecular weight of the carrier to primary chains below the renal threshold [115-117]. These data support our hypothesis and bode well for the success of the proposed design of backbone degradable HPMA copolymers composed of alternating segments of HPMA copolymer, with molecular weight below the renal threshold, and lysosomally degradable GFLG containing oligopeptides.

The improved therapeutic efficacy of second generation, backbone degradable HPMA copolymer conjugates has been evaluated in several studies. The examination of multiblock HPMA copolymer - doxorubicin (DOX) conjugates demonstrated molecular weight dependent antitumor activity toward human ovarian A2780/AD carcinoma xenografts in nude mice. The study revealed enhanced activity of multiblock, second- 
generation higher molecular weight conjugates ( $\mathrm{Mw}=93$; 185; and $349 \mathrm{kDa})$ when compared to traditional HPMA copolymer-DOX conjugate (Mw = $20 \mathrm{kDa})$ [118].

Similarly, a multiblock backbone degradable HPMA copolymer - paclitaxel conjugate (mP-PTX; $\mathrm{Mw}=335 \mathrm{kDa})$ possessed an enhanced blood circulation time when comopared to $1^{\text {st }}$ generation conjugates. SPECT/CT imaging and biodistribution studies demonstrated biodegradability as well as elimination of mP-PTX from the body. The tumors in the MP-PTX treated group grew more slowly than those treated with saline, free PTX, and P-PTX ( $1^{\text {st }}$ generation conjugate, $M w=48 \mathrm{kDa}$; single dose at $20 \mathrm{mg}$ $\mathrm{PTX} / \mathrm{kg}$ equivalent was administered). Histological analysis indicated that MP-PTX had no toxicity in liver and spleen, but induced massive cell death in the tumor [119].

Combination of $2^{\text {nd }}$ generation HPMA copolymer - gemcitabine and HPMA copolymer paclitaxel conjugates has shown excellent activity toward human ovarian carcinoma xenografts [87]. In vivo behavior of a combination of diblock (two polyHPMA blocks connected by a peptide degradable sequence) backbone degradable HPMA copolymerdrug conjugates (2P-PTX and 2P-GEM) was investigated using pharmacokinetics, biodistribution and SPECT/CT imaging studies. In parallel, the antitumor efficacy of combination treatment of 2P-PTX and 2P-GEM was evaluated and compared with free drugs (PTX and GEM) and first-generation low Mw conjugates (P-PTX and P-GEM) in nu/nu mice bearing A2780 tumor xenografts. Compared to first-generation low $\mathrm{Mw}$ HPMA copolymer conjugates, high Mw backbone biodegradable HPMA copolymer carriers significantly prolonged the intravascular half-life of drugs (PTX and GEM) in mice. The biodistribution and SPECT/CT imaging results demonstrated higher accumulation of conjugates 2P-PTX and 2P-GEM in the tumors and the degradation of new generation conjugates in mice. Notably, the tumors treated with combination of $2 \mathrm{P}$ PTX and 2P-GEM were more effectively repressed, when compared to free drug combination and first-generation (low Mw) conjugates combination (Fig. 3). The histological analysis indicated that the combination treatment had no toxicity in major organs [87].

Figure 3

\subsubsection{Treatment of other diseases}

Polymeric drug carriers are suitable also for the treatment of other diseases, e.g., musculoskeletal diseases [120-123]. Interestingly, bone-targeted long-circulating backbone degradable HPMA copolymer - prostaglandin $E_{1}$ conjugates had higher accumulation on bone tissue and greater indices of bone formation in an ovariectomized rat osteoporosis model when compared to $1^{\text {st }}$ generation conjugates (Fig. 4) [124].

Figure 4

\subsubsection{Colon delivery}

Most of water-soluble polymer-drug conjugates are administered intravenously. However, the colon delivery is a suitable alternative. To achieve degradation in the colon, spacers that combine a reducible aromatic azobond and a peptide group [125] or azobond and a 1,6-elimination 4-aminobenzylcarbamate group [126] have been used. Such HPMA copolymer - 9-aminocamtothecin conjugates have been successful in the treatment of experimental orthotopic and subcutaneous HT29 cancer models (Fig. 5) 
[127-129]. However, when using the oral route one has to be aware of the size limitation of transport [130].

Figure 5

\section{Self-assembled hydrogels and crosslinking of receptors}

\subsection{Coiled-coil forming peptides}

The coiled-coil is one of the folding patterns of native proteins. It consists of two or more right-handed $\alpha$-helices winding together and forming a slightly left-handed super-helix [131]. The primary structure of the coiled coil motif is characterized by a heptad repeating sequence designated as $a, b, c, d, e, f, g$, in which $a$ and $d$ are usually hydrophobic amino acid residues, while the others are polar. Two helices associate through a hydrophobic interface between $a$ and $d$ making $b, c$, and $f$ face outward. Interhelical electrostatic interactions between residues $e$ and $g$ contribute to the stability of the coiled-coil. The distinctive feature of coiled coils is the specific spatial recognition, association, and dissociation of helices, making it an ideal model of protein biomaterials in which the higher structure may be predicted based on the primary sequence. Various functional groups may be exactly positioned into the coiled-coil structure allowing specific intermolecular interactions to occur. Depending on their detailed structure, $\alpha$ helices may associate as homodimers, heterodimers in parallel or antiparallel alignments, or form higher order (e.g., tetramer) aggregates. Binding coiled-coil forming sequences to linear water-soluble polymers enhances their secondary structure slightly [132,133]. Formation of coiled-coil mediates the assembly of graft copolymers into 3D hydrogels. $[2,5-7,9,20,43,134-138]$.

Crosslinking of polymer precursors with genetically engineered protein domains. A new strategy of hybrid hydrogel synthesis entails the non-covalent attachment of genetically engineered coiled-coil protein motifs to hydrophilic synthetic HPMA copolymer backbone. The physical crosslinking was established by self-assembly of the coiled-coil domains. A temperature-induced hydrogel collapse was observed that corresponded to the structural transition of the coiled-coil domains from an elongated helix to an unfolded state. Hydrogels formed by crosslinking of HPMA copolymer precursors with coiled-coil modules underwent dramatic volume transitions (de-swelling up to 10-fold) at the melting temperature of the coiled-coil modules [134]. This is a new temperature response mechanism for hydrogels that can be tuned over a wide temperature range by assembling gels with coiled-coils that have different melting temperatures [139]. These results seemed to indicate that the properties of a well-defined coiled-coil protein motif can be imposed onto a hybrid hydrogel containing synthetic polymer-based primary chains. Given the immense potential of tailoring material properties with genetically engineered proteins this strategy adds a new dimension to the field of "smart" hydrogelbased biomaterials $[20,140]$.

Hydrogels self-assembled from graft copolymers via formation of coiled-coil antiparallel heterodimers Recently, self-assembly of graft copolymers into hybrid hydrogels was demonstrated [6,9]. A novel hybrid hydrogel system based on HPMA copolymers consisted of a hydrophilic polymer backbone and a pair of oppositely charged peptide grafts. Two distinct pentaheptad peptides (CCE and CCK) were designed to create a dimerization motif and serve as physical crosslinkers. Consequently, the graft copolymers, CCE-P ( $P$ is the HPMA copolymer backbone) and CCK-P, self-assembled 
into hybrid hydrogels in situ; the process was modulated by the formation of antiparallel heterodimeric coiled-coils [6,9]. This approach possesses the advantage of decreased steric hindrance of the polymer backbone due to the "in-register" alignment of the peptide grafts. Equimolar mixtures of the graft copolymers, CCE-P/CCK-P, have been observed to self-assemble into hydrogels in PBS (phosphate buffer) solution at neutral $\mathrm{pH}$ at concentrations as low as $0.1 \mathrm{wt} \%$. The formation of these hybrid hydrogels was reversible [9]. The excellent CCE/CCK biorecognition was used by Lv et al. for the development of tandem modular protein-based hydrogels [141].

\subsection{Beta-sheet forming peptides}

Beta-sheets are important structural elements in proteins. $\beta$-Strands are aligned adjacent to each other and are stabilized by hydrogen bonds between the carbonyl oxygen of an amino acid in one strand and the backbone nitrogen of a second amino acid in another strand. The strands (at least two, but frequently more) can arrange in parallel or antiparallel fashion to form the $\beta$-sheets. The stability of $\beta$-sheets depends on the interaction of side chains of neighboring amino acids. These interactions must compensate for the loss of translational and solvation energies of the peptide [142].

Hydrogels from graft copolymers containing beta-sheet peptides were thoroughly investigated [143]. For example, the 128 immunoglobulin (Ig)-like domain of human cardiac titin was used to crosslink acrylamide copolymers into temperature sensitive hydrogels [144]. HPMA hybrid graft copolymers were prepared by attachment of $\mathrm{N}$ terminal CGG modified $\beta$-sheet peptide (CGGTTRFTWTFTTT) to polyHPMA precursor, which contained pendant maleimide groups. CD spectra showed that the strong tendency of the peptide to self-assemble into $\beta$-sheets was retained in the copolymers. In addition, $\beta$-sheet sensitivity to temperature and $\mathrm{pH}$ variations decreased due to polyHPMA shielding effect [145]. Finally, the ability of a hybrid hydrogel self-assembled from HPMA copolymers and complementary $\beta$-sheet grafts (TTRFTWTFTTT-NH $\mathrm{N}_{2}$ and TTEFTWTFETT- $\mathrm{NH}_{2}$ ) to act as scaffolds for bone tissue engineering was explored [146]. The hydrogel displayed anisotropic porosity; thus, besides support for preosteoblast cells, it provided surfaces characterized by epitaxy that favored template-driven mineralization of hydroxyapatite.

\subsection{Proteins}

Protein mutants when used as crosslinkers in hydrogels may provide specificity based on binding of calcium or a low molecular weight compound. For example calmodulin undergoes two conformational changes from the native state: into a dumbbell-like conformation when bound to $\mathrm{Ca}^{++}$, and into a more constrictive conformation when bound to phenothiazine. The hydrogel was responsive to both $\mathrm{Ca}^{++}$and phenothiazine; its incorporation into a simple microfluidic system demonstrated the hydrogel's potential to control flow [147-149]. Generally the conformational change of the protein, e.g. upon binding its substrate [150] translates into macroscopic motion.

\subsection{Oligonucleotides}

Matsuda and Nagahara [151] prepared self-assembling hydrogels by self-assembly of two poly $(N, N$-dimethylacrylamide) graft copolymers. One was grafted with oligodeoxythymilidate (oligo $\mathrm{T}_{10}$ ), the other with oligodeoxyadenylate (oligo $\mathrm{A}_{10}$ ). 


\subsection{Lessons from hydrogels self-assembled from hybrid copolymers for the design of drug-free nanomedicines}

The results of self-assembly of graft copolymers into precisely defined 3D hydrogels provided several pathwas for translation. First, it would be possible, under efficient mixing, to subcutaneously inject a mixture of two solutions, one containing a therapeutic protein. The pharmacokinetics of release could be controlled. However, this was abandoned because one can achieve similar results with cheaper polymers.

Then we formulated the following hypothesis on apoptosis induction in B cells (expressing a non-internalizing CD20 receptor) that is the base for our current research in drug-free macromolecular therapeutics:

If biorecognition of complementary coiled-coil forming peptides results in self-assembly of graft copolymers into crosslinked hydrogels

then

biorecognition of these peptides at cell surface should result in crosslinking of CD20 receptors and initiation of apoptosis.

In other words - if we know how to crosslink hydrogels we should know how to crosslink receptors if this is the mechanism for apoptosis initiation. As described in the next section, the approach was quite successful.

\subsection{Recent advances in drug-free macromolecular therapeutics}

\subsubsection{Coiled-coil-based system}

The excellent biorecognition of the peptide domains was an inspiration for the design of new nanomedicines; this created a bridge between the design of biomaterials and the design of nanomedicines. CCK and CCE peptides that self-assembly into antiparallel coiled-coil heterodimers were engaged in the design of a new CD20+ cell apoptosis induction system, called drug-free macromolecular therapeutics $[10,11]$. CD20 is an ideal target for immunotherapies. It is an integral membrane protein [152] that is expressed from pre-B cells to terminally differentiated plasma cells and is present on greater than $90 \%$ of B-cell malignancies [153]. CD20 is not shed from the cell surface nor is it present in serum under standard physiological conditions. It is a cell cycle regulatory protein that either controls or functions as a store operated calcium channel. The protein forms dynamic dimers and tetramers [154] constitutively associated in lipid rafts of the cell membrane [155].

Indeed, the biorecognition of CCE/CCK peptide motifs at the cellular surface was able to control apoptosis of CD20+ B cells. Exposure of Raji B cells to an anti-CD20 Fab'-CCE conjugate decorated the cell surface with CCE (CD2O is a non-internalizing receptor) through antigen-antibody fragment recognition. Further exposure of the decorated cells to CCK-P (grafted with multiple copies of CCK) resulted in the formation of CCE/CCK coiled-coil heterodimers at the cell surface. This second biorecognition induced the crosslinking of CD20 receptors and triggered the apoptosis of Raji B cells in vitro [10] and in a Non-Hodgkin lymphoma (NHL) animal model in vivo [11]. This is a new concept, where the biological activity of drug-free macromolecular therapeutics is based on the biorecognition of peptide motifs (Fig. 6). 
Figure 6

To prove that two conjugates assemble at cell surface, multiple fluorescence imaging studies were performed, including 2-channel FMT, 3D confocal microscopy, and 4-color FACS [156]. Confocal microscopy showed co-localization of two fluorescently labeled nanoconjugates, Fab'-CCE and P-(CCK $)_{9}$ ) on non-Hodgkin's lymphoma (NHL) Raji cell surface, indicating "two-step" targeting specificity. The fluorescent images also revealed that these two conjugates could disrupt normal membrane lipid distribution and form lipid raft clusters, leading to cancer cell apoptosis. This "two-step" biorecognition capacity was further demonstrated in a NHL xenograft model, using fluorescent images at wholebody, tissue and cell levels. We also found that delaying injection of $\mathrm{P}-(\mathrm{CCK})_{\mathrm{x}}$ could significantly enhance targeting efficacy. This high-specificity therapeutics provide a safe option to treat NHL and other B cell malignancies [156].

We evaluated the immunogenicity of the coiled-coil based drug-free macromolecular therapeutics [157]. We synthesized enantiomeric peptides (L- and D-CCE and L- and DCCK), HPMA copolymer-peptide conjugates and Fab' fragment-peptide conjugates. The immunological properties were evaluated in vitro on RAW264.7 macrophages and in vivo on immunocompetent $B A L B / c$ mice. There was no substantial difference in the ability of D-peptide and L-peptide conjugates to induce Ab response. HPMA copolymer and unconjugated peptides did not induce any response in RAW264.7 macrophages. In vivo, the therapeutics based on L-peptides (MIX L; Fab'-L-CCE/P-L-CCK) did not induce substantially different $A b$ response than those based on $D$ peptides (MIX D; Fab'-DCCE/P-D-CCK). The titer and avidity of Ab induced by i.v. treatment with MIX L or MIX D were generally low, slightly lower in case of MIX D, except for anti-Fab'-CCE IgM Ab. In general, there was detectable $A b$, but no cellular response to the therapeutics administered i.v. The Ab response was predominantly directed against the Fab' part of the therapeutics [157]. Therefore, in spite of the fact that 1F5 antibodies were used in human with minimal toxicities $[158,159]$ we suggest to humanize the Fab' fragment before moving to the clinics.

\subsubsection{Other applications of the coiled-coil system}

Biorecognition of coiled-coils has been used in many applications and several examples follow. Shen et al. controlled the accessibility of ligands by formation of coiled-coils at the surface [160]. Two peptide fragments of green fluorescent protein (GFP) were modified with coiled-coil forming peptides; following reassembly the GFP displayed its characteristic fluorescence [161]. Chelur and Chalfie demonstrated that co-expression of caspase 3 subunits generates constitutively active caspase activity that lead to cell death. The caspase activity occurred only when the subunits associated through binding of linked antiparallel coiled-coil domains [162]. Ryadnov and coworkers designed a cyclopeptide block consisting of two domains that oligomerize by forming a parallel coiled-coil heterodimer. Self-assembly leads to formation of hyperbranched fibrillar networks with nano- to micrometer size [163]. Coiled-coil formation between a peptide graft attached to a synthetic copolymer and a complementary graft containing a biologically active compound have been used for the design of novel drug delivery systems. Pechar and coworkers used coiled-coil peptides for the design of novel HPMA copolymer-based macromolecular therapeutics [164-166]. Apostolovic et al. evaluated the uptake and subcellular trafficking in B16F10 cells of HPMA copolymers containing K3 grafts dimerized with E3 peptides terminated in methotrexate $[167,168]$. Tirrell et al.pioneered the design of ABA block copolymers that assemble into hydrogels by 
biorecognition of coied-coil A blocks [169-171]. It is easy to modify the structure of A blocks to manipulate the properties of the resultinghydrogel [172].

\subsubsection{Morpholino oligonucleotide based system}

The coild-coil based system worked well. However, the peptides do not have a strong secondary structure at neutral $\mathrm{pH}$. They associate by hydrophobic and electrostatic interactions and then fold into a antiparallel coiled-coil heterodimer. To be efficient in vivo, we use large excess of the CCK peptide ( $25 x)$ bound as grafts to the HPMA copolymer. Therefore our aim was to identify a biorecognition pair that will bind strongly at an equimolar concentration. We selected morpholino oligonucleotides due to their fast hybridization, excellent binding affinity, stability in plasma and water-solubility $[173,174]$.

To apply a similar approach for the design of drug-free nanomedicine, we designed a pair of phosphorodiamidate morpholino (MORF) oligomers (25 base pairs each), MORF1 and MORF2, as the biorecognition motifs for the second-generation "drug-free" therapeutic system [8]. The MORF oligonucleotides are charge neutral, resulting in significantly stronger binding than natural DNA and RNA [175]. The sequences of MORF1 and MORF2 were designed to achieve optimal binding efficiency and minimal off-targets with human and murine mRNA, and to prevent self-complementarity [8]. This new therapeutic system was composed of two hybrid conjugates: (1) anti-CD20 Fab' linked to MORF1 (Fab'-MORF1), and (2) HPMA copolymers grafted with multiple copies of MORF2 (P-(MORF2) $)$ ). The two conjugates self-assembled via MORF1-MORF2 hybridization at the surface of $\mathrm{CD}_{2} \mathrm{O}^{+} \mathrm{B}$-cells, which crosslinked $\mathrm{CD} 20$ and initiated apoptosis $[8,176]$.

To evaluate in vivo anticancer efficacy of the hybridization system we performed animal experiments using the same mouse model of systemic human B-NHL (Fig. 7). Mice were intravenously injected with Raji cells, followed by administration (i.v.) of the two conjugates. Results showed that, at equivalent doses, a single treatment of Fab'-MORF1 and $\mathrm{P}-(\mathrm{MORF} 2)_{9}(\mathrm{MORF} 1 \mathrm{MORF2}=1: 1)$ was significantly more effective than a single treatment of Fab'-CCE and $\mathrm{P}-(\mathrm{CCK})_{9} \quad(\mathrm{CCE}: \mathrm{CCK}=1: 25)$ on preventing lymphoma dissemination and on extending the animal survival (compare refs. 11 and 8). The efficacy of one dose treatment can be further improved by using a 5-time excess of $\mathrm{P}$ (MORF2) $\times($ MORF1:MORF2=1:5). Moreover, the time lag in the consecutive treatment can be optimized based on biodistribution and pharmacokinetics of the Fab'-MORF1 conjugate [177]. The comparison between the coiled-coil and the oligonucleotide designs clearly indicates that the hybridization system is advantageous for the drug-free approach. This is likely due to a more direct and specific binding pattern of the oligonucleotide base pairing at physiological conditions, when compared to the binding of the coiled-coil forming peptides. We also believe that the therapeutic system composed of two nanoconjugates has a greater potential for activity and decrease of side effects than the one conjugate multivalent systems [178-183].

\section{Figure 7}

We evaluated the drug-free approach in chronic lymphocytic leukemia (CLL) cells isolated from 10 patients [184]. Primary cells were treated with Fab'-MORF1 and P$($ MORF2) $x$, and apoptosis and cytotoxicity were observed in 8 samples, including 2 samples with the $17 \mathrm{p} 13$ deletion, an ultrahigh-risk prognostic factor [185]. The data suggest a p53-independent mechanism of apoptosis induction. This constitutes potential 
treatment for chemoresistant malignancies [186] and may synergize with other therapies [187]. Similarly, the approach also worked in cells from patients with mantle cell lymphoma, an aggressive subset of B-NHL that is particularly difficult to treat [177]. When compared to anti-CD20 mAbs 1F5 and rituximab, drug-free macromolecular therapeutics showed significantly more potent apoptosis-inducing activity and cytotoxicity. These results highlight the promising potential of the drug-free approach for clinical translation, as novel treatments against NHL, CLL, and other B-cell associated malignancies.

In summary, these nanoconjugates performed extremely well on an animal model in vivo $[8,177]$ and on cells from patients with chronic lymphocytic leukemia [184] and mantle cell lymphoma [177].

\section{Conclusions}

We hope that we demonstrated the close connection between the design of traditional hydrogels and the design of water-soluble polymer-drug conjugates. This connection led to the design of backbone degradable carriers of anticancer drugs that have a great translational potential. The synthesis of backbone degradable polymer carriers of drugs permits to use long-circulating conjugates without compromising their biocompatibility.

We also highligted the connection between the design of self-assembled hybrid hydrogels and drug-free macromolecular therapeutics. The latter is a new paradigm in polymer therapeutics that also possesses an excellent application promise. This system does not use low molecular weight drugs; this decreases the probability of adverse effects. The onset of apoptosis is based on the crosslinking of non-internalizing receptors mediated by association of two complementary peptides or oligonucleotides. The nanoconjugate therapeutic system can be used not only for the treatment of blood cancers but also for other diseases, including rheumatoid arthritis [188], systemic lupus erythematosus [189], prostate cancer [190], and colon cancer [191].

\section{Acknowledgments}

The research described in this overview has been supported by $\mathrm{NIH}$ grants (recently CA51578, CA132831, GM069847, EB005288, TW006260, CA156933, and GM095606), Department of Defense (recently W81XWH-13-1-0160), and University of Utah Research Foundation. We thank our coworkers and numerous collaborators. We are truly indebted to all of them; their scientific contributions are reflected in the references.

\section{References}

[1] O. Wichterle, D. Lím, Hydrophilic gels for biological use. Nature 185 (1960) 117118.

[2] J. Kopeček, Hydrogels: From soft contact lenses and implants to self-assembled nanomaterials. J. Polym. Sci.: Part A: Polym. Chem. 47 (2009) 5929-5946.

[3] O. Wichterle (Czechoslovak Academy of Sciences), U.S. Patents 3,660,545; $3,408,429 ; 3,496,254 ; 3,499,862$.

[4] J. Kopeček, L. Šprincl, Relationship between the structure and biocompatibility of hydrophilic gels. Polim. Med. 4 (1974) 109-117. 
[5] J. Kopeček, J. Yang, Smart self-assembled hybrid hydrogel biomaterials. Angew. Chem. Int. Ed. 51 (2012) 7396-7417.

[6] J. Yang, C. Xu, C. Wang, J. Kopeček, Refolding hydrogels self-assembled from $\mathrm{N}$ (2-hydroxypropyl)methacrylamide graft copolymers by antiparallel coiled-coil formation. Biomacromolecules 7 (2006) 1187-1195.

[7] J. Kopeček, J. Yang, Peptide-directed self-assembly of hydrogels. Acta Biomaterialia 5 (2009) 805-816.

[8] T.-W. Chu, J. Yang, R. Zhang, M. Sima, J. Kopeček, Cell surface self-assembly of hybrid nanoconjugates via oligonucleotide hybridization induces apoptosis. ACS Nano 8 (2014) 719-730.

[9] J. Yang, K. Wu, Č. Koňák, J. Kopeček, Dynamic light scattering study of the selfassembly of HPMA hybrid graft copolymers. Biomacromolecules 9 (2008) 510-517.

[10] K. Wu, J. Liu, R.N. Johnson, J. Yang, J. Kopeček, Drug-free macromolecular therapeutics: Induction of apoptosis by coiled-coil mediated crosslinking of antigens on cell surface. Angew. Chem. Int. Ed. 49 (2010) 1451-1455.

[11] K. Wu, J. Yang, J. Liu, J. Kopeček, Coiled-coil based drug-free macromolecular therapeutics: In vivo efficacy. J. Control. Release 157 (2012) 126-131.

[12] D. Lím, Personal communication, 2001.

[13] D. Lím, Gels with controllable water content prepared by polymerization (in Czech) RNDr. Thesis, Technical University Prague, 1953.

[14] O. Wichterle, in Encyclopedia of Polymer Science and Technology; H.F. Mark, N.G. Gaylord, N. Bikales, Eds., Interscience, New York, NY, 1971, Vol. 15, pp. 273-291.

[15] L. Krejčí, R. Harrison, O. Wichterle, Hydroxyethyl methacrylate capillary strip. Animal trials with a new glaucoma drainage device. Arch. Ophthal. 84 (1970) 76-82.

[16] Z. Kresa, J. Rems, O. Wichterle, Hydron gel implants in vocal cords. Arch. Otholaryngol. 76 (1973) 360-365.

[17] A. Křístek, B. König, O. Wichterle, A contribution to the surgical treatment of retinal detachment. (Experience with the use of polyglycolmethacrylate as material for implants in the Custodis operation) (in German). Klin. Monbl. Augenheilkd. 149 (1966) 219-227.

[18] J. Hubáček, K. Kliment, J. Dušek, Jar. Hubáček, Tissue reaction after implantation and in situ polymerization of hydrophilic gels. J. Biomed. Mater. Res. 1 (1967) 387394.

[19] J. Hubáček, O. Wichterle, K. Kliment, Jar. Hubáček, J. Dušek, Experiences with neutral hydrophilic gel in surgery of the middle ear. Ceskoslov. otolaryngologie (in Czech) 17 (1968) 211-215.

[20] J. Kopeček, J. Yang, Hydrogels as Smart Biomaterials. Polymer Int. 56 (2007) 1078-1098.

[21] Hydrogels for Medical and Related Applications, J.D. Andrade, Ed., ACS Symposium Series, Vol 31, Washington D.C., 1976.

[22] B.D. Ratner, A. Hoffman, in Hydrogels for Medical and Related Applications, J.D. Andrade, Ed., ACS Symposium Series, Vol 31; Washington D.C., 1976, pp. 1-36.

[23] V. Kůdela, Hydrogels, in Encyclopedia of Polymer Science and Engineering; H.F. Mark, J. Kroschwitz, Eds., Wiley, New York, NY, 1987, pp 783-807.

[24] Hydrogels in Medicine and Pharmacy, Vol. I-III, N.A. Peppas, Ed., CRC Press, Boca Raton, FL, 1987.

[25] B.D. Ratner, S.J. Bryant, Biomaterials: Where we have been and where we are going. Annu. Rev. Biomed. Eng. 6 (2004) 41-75.

[26] L. Šprincl, J. Vacík, J. Kopeček, D. Lím, Biological tolerance of poly(N-substituted methacrylamides). J. Biomed. Mater. Res. 5 (1971) 197-205.

[27] J. Kopeček, L. Šprincl, H. Bažilová, J. Vacík, Biological tolerance of poly $(N$ substituted acrylamides). J. Biomed. Mater. Res. 7 (1973) 111-121.

[28] L. Šprincl, J. Vacík, J. Kopeček, D. Lím, Biological tolerance of ionogenic hydrophilic gels. J. Biomed. Mater. Res. 7 (1973) 123-136. 
[29] K. Ulbrich, L. Šprincl, J. Kopeček, Biocompatibility of poly(2,4-pentadiene-10l). J. Biomed. Mater. Res. 8 (1974) 155-161.

[30] L. Šprincl, J. Kopeček, D. Lím, Effect of porosity of heterogeneous poly(glycol monomethacrylate) gels on the healing-in of test implants. J. Biomed. Mater. Res. 5 (1971) 447-458.

[31] L. Šprincl, J. Kopeček, D. Lím, Effect of the structure of poly(glycol monomethacrylate) gels on the calcification of implants. Calc. Tiss. Res. 13 (1973) 63-72.

[32] J. Kopeček, D. Lím, Mechanism of three-dimensional polymerization of glycol methacrylates. II. The system glycol monomethacrylate - glycol dimethacrylates solvents. J. Polym. Sci. A-1, 9 (1971) 147-154.

[33] Z. Voldřich, Z. Tománek, J. Vacík, J. Kopeček, Long-term experience with the poly(glycol monomethacrylate) gel in plastic operations of the nose. J. Biomed. Mater. Res. 9 (1975) 675-685.

[34] J. Červený, L. Šprincl, The calcification of poly(glycol methacrylate) gels in experimental and clinical practice. Polim. Med. 11 (1981) 71-78.

[35] A.S. Hoffman, Environmentally sensitive polymers and hydrogels. MRS Bulletin, (1991 September) pp. 42-46.

[36] J. Kopeček, J. Vacík, D. Lím, Permeability of membranes containing ionogenic groups. J. Polym. Sci. A-1, 9 (1971) 147-154.

[37] J. Vacík, J. Kopeček, Specific resistances of hydrophilic membranes containing ionogenic groups. J. Appl. Polym. Sci. 19 (1975) 3029-3044.

[38] Y.H. Bae, T. Okano, R. Hsu, S.W. Kim, Thermo-sensitive polymers as on-off switches for drug release. Makromol. Chem. Rapid Commun. 8 (1988) 481-485.

[39] K. Dušek, D. Patterson, Transition in swollen polymer networks induced by intramolecular condensation. J. Polym. Sci., Part A-2, 6 (1968) 1209-1216.

[40] T. Tanaka, D. Fillmore, S.-T. Sun, I. Nishio, G. Swislow, A. Shah, Phase transition in ionic gels. Phys. Rev. Lett. 45 (1980) 1636-1639.

[41] J. Hrouz, M. Ilavský, K. Ulbrich, J. Kopeček, The photoelastic behaviour of dry and swollen networks of poly( $N, N$-diethylacrylamide) and of its copolymers with $\mathrm{N}$ tert.butylacrylamide. Europ. Polym. J. 17 (1981) 361-366.

[42] A. Suzuki, T. Tanaka, Phase transition in polymer gels induced by visible light. Nature 346 (1990) 345-347.

[43] C. Wang, Hybrid hydrogels assembled from synthetic polymers and engineered protein domains. Ph.D. Dissertation, Department of Bioengineering, University of Utah, 2001.

[44] J. Kopeček, P. Rejmanová, Enzymatically degradable bonds in synthetic polymers. In: Controlled Drug Delivery, S.D. Bruck (Ed.), CRC Press, Boca Raton, Florida, Vol. I, 1983, pp. 81-124.

[45] K. Ulbrich, J. Strohalm, J. Kopeček, Polymers containing enzymatically degradable bonds. VI. Hydrophilic gels cleavable by chymotrypsin. Biomaterials 3 (1982) 150154.

[46] J. Kopeček, J. Jokl, D. Lím, Mechanism of three-dimensional polymerization of glycol methacrylates (in German). J. Polym. Sci. C 16 (1968) 3877-3889.

[47] J. Kopeček, D. Lím, Mechanism of three-dimensional polymerization of glycol methacrylates. III. Contribution to the polymerization kinetics of the system diglycol monomethacrylate - glycol dimethacrylates - water. Collection Czechoslov. Chem. Commun. 36 (1971) 2703-2707.

[48] J. Kopeček, D. Lím, Mechanism of three-dimensional polymerization of glycol methacrylates. IV. The System triglycol monomethacrylate - glycol dimethacrylates - water, Collection Czechoslov. Chem. Commun. 36 (1971) 3394-3398.

[49] K. Ulbrich, J. Kopeček, Radical polymerization of $N$-substituted methacrylamides, Europ. Polym. J. 12 (1976) 183-187. 
[50] J. Kopeček, L. Šprincl, D. Lím, New types of synthetic infusion solutions. I. Investigation of the effect of solutions of some hydrophilic polymers on blood. J. Biomed. Mater. Res. 7 (1973) 179-191.

[51] L. Šprincl, J. Exner, O. Štěrba, J. Kopeček, New types of synthetic infusion solutions. III. Elimination and retention of poly[ $N$-(2-hydroxypropyl)methacrylamide] in a test organism. J. Biomed. Mater. Res. 10 (1976) 953-963.

[52] E. Paluska, J. Činátl, L. Korčáková, O. Štěrba, J. Kopeček, A. Hrubá, J. Nezvalová, R. Staněk, Immunosuppressive effect of a synthetic polymer - poly[ $N$ - $(2-$ hydroxypropyl)methacrylamide] (Duxon). Folia Biologica 26 (1980) 304-311.

[53] E. Paluska, A. Hrubá, O. Štěrba, J. Kopeček, Effect of a synthetic poly[N-(2hydroxypropyl)methacrylamide] (Duxon) on haemopoiesis and graft versus host reaction. Folia biologica 32 (1986) 91-102.

[54] J. Kopeček, Soluble polymers in medicine, in: D.F. Williams (Ed.), Systemic Aspects of Biocompatibility, Vol. II, CRC Press, Boca Raton, Florida, 1981, pp. 159-180.

[55] J. Kopeček, H. Bažilová, Poly[N-(2-hydroxypropyl)methacrylamide]. 1. Radical polymerization and copolymerization. Europ. Polym. J. 9 (1973) 7-14.

[56] J. Strohalm, J. Kopeček, Poly[N-(2-hydroxypropyl)methacrylamide]. IV. Heterogeneous polymerization. Angew. Makromol. Chem. 70 (1978) 109-118.

[57] M. Bohdanecký, H. Bažilová, J. Kopeček, Poly[N-(2-hydroxypropyl)methacrylamide]. II. Hydrodynamic properties of diluted polymer solutions. Europ. Polym. J. 10 (1974) 405-410.

[58] J. Kopeček, Soluble biomedical polymers. Polim. Med. 7 (1977) 191-221.

[59] D. Putnam, J. Kopeček, Polymers with anticancer activity. Adv. Polym. Sci. 122 (1995) 55-123.

[60] S.D. Conner, S.L. Schmid, Regulated portals of entry into the cell. Nature 422 (2003) 37-44.

[61] J. Liu, H. Bauer, J. Callahan, P. Kopečková, H. Pan, J. Kopeček, Endocytic uptake of a large array of HPMA copolymers: Elucidation into the dependence on the physicochemical characteristics. J. Control. Release 143 (2010) 71-79.

[62] T.M. Allen, Ligand-targeted therapeutics in anticancer therapy, Nat. Rev. Cancer 2 (2002) 750-763.

[63] A. David, P. Kopečková, T. Minko, A. Rubinstein, J. Kopeček, Design of multivalent galactoside ligand for selective targeting of HPMA copolymers-doxorubicin conjugates to human colon cancer cells. Eur. J. Cancer 40 (2004) 148-157.

[64] J.-G. Shiah, Y. Sun, P. Kopečková, C.M. Peterson, R.C. Straight, J. Kopeček, Combination chemotherapy and photodynamic therapy of targetable $\mathrm{N}$-(2hydroxypropyl)methacrylamide copolymer - doxorubicin/mesochlorin $\mathrm{e}_{6}$ - OV-TL16 antibody immunoconjugates,.J. Control. Release 74 (2001) 249-253.

[65] J. Kopeček, Controlled degradability of polymers - a key to drug delivery systems. Biomaterials 5 (1984) 19-25.

[66] Y. Zhou, J. Kopeček, Biological rationale for the design of polymeric anti-cancer nanomedicines. J. Drug Target. 21 (2013) 1-26.

[67] H. Ringsdorf, Structure and properties of pharmacologically active polymers, J. Polym. Sci., Polym. Symp. 51 (1975) 135-153.

[68] J. Kopeček, P. Kopečková, Design of polymer-drug conjugates. In: Drug Delivery in Oncology, F. Kratz, P. Senter, H. Steinhagen, Eds., Wiley-VCH, Weinheim, Germany, Vol. 2, Chapter 17, 2012, pp.485-512.

[69] J. Kopeček, Polymer - drug conjugates: Origins, progress to date and future directions, Adv. Drug Deliv. Rev. 65 (2013) 49-59.

[70] K. Ulbrich, V. Šubr, Polymeric anticancer drugs with $\mathrm{pH}$-controlled activation. Adv, Drug Deliv. Rev. 56 (2004) 1023-1050.

[71] H. Maeda, Tumor-selective delivery of macromolecular drugs via the EPR effect: background and future prospects. Bioconjugate Chem. 21 (2010) 797-802. 
[72] H. Maeda, Toward a full understanding of the EPR effect in primary and metastatic tumors as well as issues related to its heterogeneity. Adv. Drug Deliv. Rev. (2015) doi: 10.1016/j.addr.2015.01.002.

[73] Y. Zhou, J. Yang, J. Kopeček, Cancer stem cells: Potential target for anti-cancer nanomedicines. In: Tailored Polymer Architectures for Pharmaceutical and Biomedical Applications, C. Scholz, J. Kressler, Eds., ACS Symp. Series 1135, American Chemical Society, Washington, D.C., Chapter 9, 2013, pp. 127-149.

[74] C. Li, S. Wallace, Polymer-drug conjugates: Recent development in clinical oncology. Adv. Drug Delivery Rev. 60 (2008) 886-898.

[75] R. Duncan, M.J. Vicent, Polymer therapeutics - prospects for $21^{\text {st }}$ century: the end of the beginning. Adv. Drug Deliv. Rev. 65 (2013) 60-70.

[76] Z.-R. Lu, Molecular imaging of HPMA copolymers: visualizing drug delivery in cell, mouse and man. Adv. Drug Deliv. Rev. 62 (2010) 246-257.

[77] J. Kopeček, Biodegradation of polymers for biomedical use. In: IUPAC Macromolecules, H. Benoit, P. Rempp, Eds., Pergamon Press, Oxford, 1982, pp. 305-320.

[78] N.L. Krinick, Y. Sun, D. Joyner, J.D. Spikes, R.C. Straight, J. Kopeček, A polymeric drug delivery system for the simultaneous delivery of drugs activatable by enzymes and/or light. J. Biomat. Sci. Polym. Ed. 5 (1994) 303-324.

[79] C.M. Peterson, J.M. Lu, Y. Sun, C.A. Peterson, J.-G. Shiah, R.C. Straight, J. Kopeček, Combination chemotherapy and photodynamic therapy with $\mathrm{N}$-(2hydroxypropyl)methacrylamide copolymer-bound anticancer drugs inhibit human ovarian carcinoma heterotransplanted in nude mice. Cancer Res. 56 (1996) 39803985.

[80] J.M. Lu, C.M. Peterson, J.-G. Shiah, Z.-W. Gu, C.A. Peterson, R.C. Straight, J. Kopeček, Cooperativity between free and $\mathrm{N}$-(2-hydroxypropyl)methacrylamide copolymer bound adriamycin and mesochlorin $e_{6}$ monoethylene diamine induced photodynamic therapy in human epithelial ovarian carcinoma in vivo. Int. J. Oncol. 15 (1999) 5-16.

[81] J.-G. Shiah, Y. Sun, C.M. Peterson, J. Kopeček, Biodistribution of free and N-(2hydroxypropyl)methacrylamide copolymer-bound meso chlorin $\mathrm{e}_{6}$ and adriamycin in nude mice bearing human ovarian carcinoma OVCAR-3 xenografts. J. Control. Release 61 (1999) 145-157.

[82] J.-G. Shiah, Y. Sun, C.M. Peterson, R.C. Straight, J. Kopeček, Antitumor activity of $\mathrm{N}$-(2-hydroxypropyl)methacrylamide copolymer-meso chlorin $\mathrm{e}_{6}$ and adriamycin conjugates in combination treatments. Clin. Cancer Res. 6 (2000) 1008-1015.

[83] J. Hongrapipat, P. Kopečková, S. Prakongpan, J. Kopeček, Enhanced antitumor activity of combinations of free and HPMA copolymer-bound drugs. Int. J. Pharm. 351 (2008) 259-270.

[84] J. Hongrapipat, P. Kopečková, J. Liu, S. Prakongpan, J. Kopeček, Combination chemotherapy and photodynamic therapy with Fab' fragment targeted HPMA copolymer conjugates in human ovarian carcinoma cells. Mol. Pharm. 5 (2008) 696-709.

[85] N. Larson, J. Yang, A. Ray, D.L. Cheney, H. Ghandehari, J. Kopeček, Ovarian cancer combination therapy using biodegradable multiblock poly[ $\mathrm{N}-(2-$ hydroxypropyl)methacrylamide gemcitabine and paclitaxel conjugates. Int. $\mathrm{J}$. Pharm. 454 (2013) 435-443.

[86] A. Duangjai, K. Luo, Y. Zhou, J. Yang, J. Kopeček, Combination cytotoxicity of backbone degradable HPMA copolymer gemcitabine and platinum conjugates toward human ovarian carcinoma cells. Eur. J. Pharm. Biopharm. 87 (2014) 187196

[87] R. Zhang, J. Yang, M. Sima, Y. Zhou, J. Kopeček, Sequential combination therapy of ovarian cancer with backbone degradable HPMA copolymer paclitaxel and gemcitabine conjugates. Proc. Natl. Acad. Sci. USA 111 (2014) 12181-12186. 
[88] M.J. Vicent, F. Greco, R.I. Nicholson, A. Paul, P.C. Griffiths, R. Duncan, Polymer therapeutics designed for a combination therapy of hormone-dependent cancer. Angew. Chem. Int. Ed. 44 (2005) 4061-4066.

[89] E. Segal, H. Pan, P. Ofek, T. Ugadawa, P. Kopečková, J. Kopeček, R. SatchiFainaro, Targeting angiogenesis-dependent calcified neoplasms using combined polymer therapeutics. PLoS ONE 4 (4) (2009) e5233; doi: 10.1371/journal.pone.0005233.

[90] E. Segal, H. Pan, L. Benayoun, P. Kopečková, Y. Shaked, J. Kopeček, R. SatchiFainaro, Enhanced antitumor activity and safety profile of targeted nano-scaled HPMA copolymer - alendronate - TNP470 conjugate in the treatment of bone malignancies. Biomaterials 32 (2011) 4450-4463.

[91] Y. Zhou, J. Yang, J. Kopeček, Selective inhibitory effect of HPMA copolymercyclopamine conjugate on prostate cancer stem cells. Biomaterials 33 (2012) 1863-1872.

[92] Y. Zhou, J. Yang, J. Rhim, J. Kopeček, HPMA copolymer-based combination therapy toxic to both prostate cancer sem/progenitor cells and differentiated cells induces durable anti-tumor effects. J. Control. Release 172 (2013) 946-953.

[93] M. Shackleton, E. Quintana, E.R. Fearon, S.J. Morrison, Heterogeneity in cancer: cancer stem cells versus clonal evolution. Cell 138 (2009) 822-829.

[94] J.E. Dick, Looking ahead in cancer stem cell research. Nat. Biotechnol. 27 (2009) 44-46.

[95] E. Bourseau-Guilmain, J. Béjaud, A. Griveau, N. Lautram, F. Hindré, M. Weyland, J.P. Benoit, E. Garcion, Development and characterization of immuno-nanocarreris targeting the cancer stem cell marker AC133. Int. J. Pharm. 423 (2011) 93-101.

[96] J. Miki, B. Furusato, H. Li, Y. Gu, H. Takahashi, S. Egawa, I.A. Sesterhenn, D.G. McLeod, S. Srivastava, J.S. Rhim, Identification of putative stem cell markers, CD133 and CXCR4, in hTERT-immortalized primary nonmalignant and malignant tumor-derived human prostate epithelial cell lines and in prostate cancer specimens. Cancer Res. 67 (2007) 3153-3161.

[97] "Top story", Prostate Cell News 4.36 September 20, 2013.

[98] S. Kunjachan, B. Rychlík, G. Storm, F. Kiessling, T. Lammers, Multidrug resistance: Physiological principles and nanomedical solutions. Adv. Drug Deliv. Rev. 65 (2013) 1852-1865.

[99] S.G. Aller, J. Yu, A. Ward, Y. Weng, S. Chittaboina, R. Zhuo, P.M. Harrell, Y.T. Trinh, Q. Zhang, I.L. Urbatsch, G. Chang, Structure of P-glycoprotein reveals a molecular basis for poly-specific drug binding. Science 323 (2009) 1718-1722.

[100] Y.K. Zhang, Y.J. Wang, P. Gupta, Z.S. Chen, Multidrug resistance proteins (MRPs) and cancer therapy. AAPS J. (2015) Epub ahead of print (April 4).

[101] K.D. Tew. Gluthatione-associated enzymes in anticancer drug resistance, Cancer Res. 54 (1994) 4313-4320.

[102] J.L. Markman, A. Rekenechetskiy, E. Holler, J.Y. Ljubimova, Nanomedicine therapeutic approaches to overcome cancer resistance. Adv. Drug Deliv. Rev. 65 (2013) 1866-1879.

[103] V. Omelyanenko, P. Kopečková, C. Gentry, J.-G. Shiah, J. Kopeček, HPMA copolymer - anticancer drug - OV-TL16 antibody conjugates. 1. Influence of the method of synthesis on the binding affinity to OVCAR-3 ovarian carcinoma cells in vitro. J. Drug Targeting 3 (1996) 357-373.

[104] V. Omelyanenko, P. Kopečková, C. Gentry, J. Kopeček, Targetable HPMA copolymer - adriamycin conjugates. Recognition, internalization, and subcellular fate. J. Control. Release 53 (1998) 25-37.

[105] V. Omelyanenko, C. Gentry, P. Kopečková, J. Kopeček, HPMA copolymer anticancer drug - OV-TL16 antibody conjugates. 2. Processing in epithelial ovarian carcinoma cells in vitro. Int. J. Cancer 75 (1998) 600-608. 
[106] T. Minko, P. Kopečková, J. Kopeček, Comparison of the anticancer effect of free and HPMA copolymer-bound adriamycin in human ovarian carcinoma cells. Pharmaceutical Res. 16 (1999) 986-996.

[107] L.W. Seymour, R. Duncan, J. Strohalm, J. Kopeček, Effect of molecular weight of $\mathrm{N}$-(2-hydroxypropyl)methacrylamide copolymers on body distribution and rate of excretion after subcutaneous, intraperitoneal and intravenous administration to rats. J. Biomed. Mater. Res. 21 (1987) 1341-1358. (1987)

[108] M. Dvořák, P. Kopečková, J. Kopeček, High-molecular weight HPMA copolymer adriamycin conjugates. J. Control. Release 60 (1999) 321-332.

[109] J.-G. Shiah, M. Dvořák, P. Kopečková, Y. Sun, C.M. Peterson, J. Kopeček, Biodistribution and antitumor efficacy of long-circulating N-(2hydroxypropyl)methacrylamide copolymer-doxorubicin conjugates in nude mice. Eur. J. Cancer 37 (2001) 131-139.

[110] G. Moad, E. Rizzardo, S.H. Thang, Toward living radical polymerization. Acc. Chem. Res. 41 (2008) 1133-1142.

[111] C.W. Scales, Y.A. Vasilieva, A.J. Convertine, A.B. Lowe, C.L. McCormick, Direct, controlled synthesis of the nonimmunogenic, hydrophilic polymer, poly $(\mathrm{N}-(2-$ hydroxypropyl)methacrylamide) via RAFT in aqueous media. Biomacromolecules 6 (2005) 1846-1850.

[112] C.D. Hein, X.M. Liu, D. Wang, Click chemistry, a powerful tool for pharmaceutical sciences. Pharm. Res. 25 (2008) 2216-2230.

[113]J.C. Jewett, C.R. Bertozzi, Cu-free click cycloaddition reactions in chemical biology. Chem. Soc. Rev. 39 (2010) 1272-1279.

[114] C.E. Hoyle, C.N. Bowman, Thiol-ene click chemistry. Ang. Chem. Int. Ed., 49 (2010) 1540-1573.

[115] J. Yang, K. Luo, H. Pan, P. Kopečková, J. Kopeček, Synthesis of biodegradable multiblock copolymers by click coupling of RAFT-generated heterotelechelic polyHPMA conjugates. React. Funct. Polym. 71 (2011) 294-302.

[116] K. Luo, J. Yang, P. Kopečková, J. Kopeček, Biodegradable multiblock N-(2hydroxypropyl)methacrylamide copolymers via reversible addition-fragmentation chain transfer polymerization and click chemistry. Macromolecules 44 (2011) 24812488.

[117] H. Pan, J. Yang, P. Kopečková, J. Kopeček, Backbone degradable multiblock N-(2hydroxypropyl)methacrylamide copolymer conjugates via reversible additionfragmentation chain transfer polymerization and thiol-ene coupling reaction. Biomacromolecules 12 (2011) 247-252.

[118] H. Pan, M. Sima, J. Yang, J. Kopeček, Synthesis of long-circulating, backbone degradable HPMA copolymer-doxorubicin conjugates and evaluation of molecularweight-dependent antitumor efficacy. Macromol. Biosci. 13 (2013) 155-160.

[119] R. Zhang, K. Luo, J. Yang, M. Sima, Y. Sun, M.M. Janát-Amsbury, J. Kopeček, Synthesis and evaluation of a backbone biodegradable multiblock HPMA copolymer nanocarrier for the systemic delivery of paclitaxel. J. Control. Release 166 (2013) 66-74.

[120] D. Wang, S. Miller, P. Kopečková, J. Kopeček, Bone-targeting macromolecular therapeutics, Adv. Drug Deliv. Rev. 57 (2005) 1049-1076.

[121] S. A. Low, J. Kopeček, Targeting polymer therapeutics to bone, Adv. Drug Deliv. Rev. 64 (2012) 1189-1204.

[122] X.M. Liu, S.C. Miller, D. Wang, Beyond oncology - application of HPMA copolymers in non-cancerous diseases, Adv. Drug Deliv. Rev. 62 (2010) 258-271.

[123] L. Quan, Y. Zhang, B.J. Crielaard, A. Dusad, S.M. Lele, C.J. Rijcken, J.M. Metsalaar, H. Kostková, T. Etrych, K. Ulbrich, F. Kiessling, T.R. Mikuls, W.E. Hennink, G. Storm, T. Lammers, D. Wang, Nanomedicines for inflammatory arthritis: Head-to-head comparison of glucocorticoid-containing polymers, micelles, and liposomes, ACS Nano 8 (2014) 458-466. 
[124] H. Pan, M. Sima, S.C. Miller, P. Kopečková, J. Yang, J. Kopeček, Efficiency of high molecular weight backbone degradable HPMA copolymer-prostaglandin E1 conjugate in promotion of bone formation in overiectomized rats. Biomaterials 34 (2013) 6528-6538.

[125] S. Sakuma, Z.-R. Lu, P. Kopečková, J. Kopeček, Biorecognizable HPMA copolymer-drug conjugates for colon delivery of 9-aminocamptothecin. J. Control. Release 75 (2001) 365-379.

[126] S. Gao, Z.-R. Lu, B. Petri, P. Kopečková, J. Kopeček, Colon-specific 9aminocamtothecin-HPMA copolymer conjugates containing a 1,6-elimination spacer. J. Control. Release 110 (2006) 323-331.

[127] S. Gao, Z.-R. Lu, P. Kopečková, J. Kopeček, Biodistribution and pharmacokinetics of colon-specific HPMA copolymer - 9-aminocamptothecin conjugate in mice. J. Control. Release 117 (2007) 179-185.

[128] S.-Q. Gao, Y. Sun, P. Kopečková, C.M. Peterson, J. Kopeček, Pharmacokinetic modeling of absorption behavior of 9-aminocamptothecin (9-AC) released from colon-specific HPMA copolymer - 9-AC conjugate in rats. Pharmaceutical Res. 25 (2008) 218-226.

[129] S. Gao, Y. Sun, P. Kopečková, C.M. Peterson, J. Kopeček, Antitumor efficacy of colon-specific HPMA copolymer - 9-aminocamptothecin conjugate in mice bearing human colon carcinoma xenografts. Macromol. Biosci. 9 (2009) 1135-1142.

[130] H. Ghandehari, P.L. Smith, H. Ellens, P.-Y. Yeh, J. Kopeček, Size-dependent permeability of hydrophilic probes across rabbit colonic epithelium. J. Pharmacol. Exp. Ther. 280 (1997) 747-753.

[131] Y.B. Yu, Coiled-coils: stability, specificity, and drug delivery potential. Adv. Drug Deliv. Rev. 54 (2002) 1113-1129.

[132] M. Pechar, P. Kopečková, L. Joss, J. Kopeček, Associative diblock copolymers of poly(ethylene glycol) and coiled coil peptides. Macromol. Biosci. 2 (2002) 199-206.

[133] G.W.M. Vandermeulen, D. Hindenberger, H. Xu, S.S. Sheiko, H.-A. Klok, Structure and dynamics of self-assembled poly(ethylene glycol) based coiled-coil nanoobjects. ChemPhysChem 5 (2004) 488-494.

[134] C. Wang, R.J. Stewart, J. Kopeček, Hybrid hydrogels assembled from synthetic polymers and coiled-coil protein domains. Nature 397 (1999) 417-420.

[135] J. Kopeček, A. Tang, C. Wang, R.J. Stewart, De novo design of biomedical polymers. Hybrids from synthetic macromolecules and genetically engineered protein domains. Macomol. Symp. 174 (2001) 31-42.

[136] J. Kopeček, Genetically engineered protein motifs in the design of novel polymers and drug delivery systems. In: Contemporary Topics in Advanced Polymer Science and Technology, Q.-F. Zhou, S.Z.D. Cheng, Eds., Peking University Press, 2004, pp. 374-386.

[137] J. Kopeček, Smart and genetically engineered biomaterials and drug delivery systems. Eur. J. Pharmaceutical Sci. 20 (2003) 1-16.

[138] J. Kopeček, Hydrogel biomaterials: A smart future? Biomaterials 28 (2007) 51855192.

[139] C. Wang, J. Kopeček, R.J. Stewart, Hybrid hydrogels crosslinked by genetically engineered coiled-coil block proteins. Biomacromolecules, 2 (2001) 912-920.

[140] J. Kopeček, Swell Gels. Nature 417 (2002) 388-391.

[141] S. Lv, Y. Cao, H. Li, Tandem modular protein-based hydrogels constructed using a novel two-component approach. Langmuir 28 (2012) 2269-2274.

[142] S. Kyle, A. Aggeli, E. Ingham, M.J. McPherson, Production of self-assembling biomaterials for tissue engineering. Trends Biotechnol. 27 (2009) 423-433.

[143] J. Kopeček, J. Yang, Smart self-assembled hybrid hydrogels. Ang. Chem. Int. Ed. 51 (2012) 7396-7417. 
[144] L. Chen, J. Kopeček, R. J. Stewart, Responsive hybrid hydrogels with volume transitions modulated by a titin immunoglobulin module. Bioconjugate Chem. 11 (2000) 734-740.

[145] L. Radu-Wu, J. Yang, K. Wu, J. Kopeček, Self-assembled hydrogels from poly[N(2-hydroxypropyl)methacrylamide] grafted with $\beta$-sheet peptides. Biomacromolecules 10 (2009) 2319-2327.

[146] L. Wu, J. Yang, J. Kopeček, Hybrid hydrogels self-assembled from graft copolymers containing complementary $\beta$-sheets as hydroxyapatite nucleation scaffolds. Biomaterials 32 (2011) 5341-5353.

[147] J.D. Ehrick, S.K. Deo, T.W. Browning, L.G. Bachas, M.J. Madou, S. Daunert, Genetically engineered protein in hydrogels tailors stimuli-responsive characteristics. Nature Mater. 4 (2005) 298-302.

[148] W. L. Murphy, W. S. Dillmore, J. Modica, M. Mrksich, Dynamic hydrogels: translating a protein conformational change into macroscopic motion. Angew. Chem. Int. Ed. 46 (2007) 3066-3069.

[149] Z. Sui, W. J. King, W. L. Murphy, Dynamic materials based on a protein conformational change. Adv. Mater. 19 (2007) 3377-3380.

[150] W. Yuan, J. Yang, P. Kopečková, J. Kopeček, Smart hydrogels containing adenylate kinase: Translating substrate recognition into macroscopic motion. J. Am. Chem. Soc. 130 (2008) 15760-15761.

[151] S. Nagahara, T. Matsuda, Hydrogel formation via hybridization of oligonucleotides derivatized in water-soluble vinyl polymers. Polym. Gels Netw. 4 (1996) 111-127.

[152] D.A. Einfeld, J.P. Brown, M.A. Valentine, E.A. Clark, J.A. Ledbetter, Molecular cloning of the human $B$ cell CD20 receptor predicts a hydrophobic protein with multiple transmembrane domains. EMBO J. 7 (1988) 711-717.

[153] O.W. Press, J. Howell-Clark, S. Anderson, I. Bernstein, Retention of B-cell-specific monoclonal antibodies by human lymphoma cells. Blood 83 (1994) 1390-1397.

[154] J.K. Bubien, L.J. Zhou, P.D. Bell, R.A. Frizzell, T.F. Tedder, Transfection of the CD20 cell surface molecule into ectopic cell types generates a $\mathrm{Ca}^{2+}$ conductance found constitutively in B lymphocytes. J. Cell Biol. 121 (1993) 1121-1132.

[155] J.P. Deans, H. Li, M. Polyak, CD20-mediated apoptosis: signaling through lipid rafts. Immunology 107 (2002) 176-182.

[156] R. Zhang, J. Yang, T.-W. Chu, J.M. Hartley, J. Kopeček, Multimodality imaging of coiled-coil mediated self-assembly in a drug-free" therapeutic system. Adv. Healthcare Mat. (2015) doi: 10.1002/admh.201400679.

[157] M. Kverka, J.M. Hartley, T.-W. Chu, J. Yang, R. Heidchen, J. Kopeček, Immunogenicity of coiled-coil based drug-free macromolecular therapeutics. Biomaterials 35 (2014) 5886-5896.

[158] O.W. Press, F. Appelbaum, J.A. Ledbetter, P.J. Martin, J. Zarling, P. Kidd, E.D. Thomas, Monoclonal antibody 1F5 (anti-CD20) serotherapy of human B cell lymphomas. Blood 69 (1987)584-591.

[159] T.A. Johnson, O.W. Press, Therapy of B-cell lymphomas with monoclonal antibodies and radioimmunoconjugates: the Seattle experience. Ann Hematol 79 (2000) 175-182.

[160] B. Liu, Y. Liu,J.J. Riesberg, W. Shen, Dynamic presentation of immobilized ligands regulated through biomolecular recognition. J. Am. Chem. Soc. 132 (2010) 1363013632.

[161] T.J. Magliery, C.G. Wilson, W. Pan, D. Mishler, I. Ghosh, A. D. Hamilton, L. Regan, Detecting protein-protein interactions with a green fluorescent protein fragment reassembly trap: Scope and mechanism. J. Am. Chem. Soc. 127 (2005) 146-157.

[162] D. S. Chelur, M. Chalfie, Targeted cell killing by reconstituted caspases. Proc. Natl. Acad. Sci. USA 104 (2007), 2283-2288. 
[163] A. Bella, S. Ray, M. Shaw, M. G. Ryadnov , Arbitrary self-assembly of peptide extracellular microscopic matrices. Angew. Chem. Int. Ed. 51 (2012) 428-431.

[164] R. Pola, R. Laga, K. Ulbrich, I. Sieglová, V. Král, M. Fábry, M. Kabešová, M. Kovář, M. Pechar, Polymer therapeutics with a coiled coil motif targeted against murine bcl1 leukemia. Biomacromolecules 14 (2013) 881-889.

[165] M. Pechar, R. Pola, R. Laga, K. Ulbrich, L. Bednárová, P. Maloň, I. Sieglová, V. Král, M. Fábry, O. Vaněk, Coiled coil peptides as universal linkers for the attachment of recombinant proteins to polymer therapeutics. Biomacromolecules. 12 (2011) 3645-3655.

[166] M. Pechar, R. Pola, R. Laga, A. Braunová, S.K. Filippov, A. Bogomolova, L. Bednárová, O. Vaněk, K. Ulbrich, Coiled coil peptides and polymer-peptide conjugates:synthesis, self-assembly, characterization and potential in drug delivery systems. Biomacromolecules 15 (2014) 2590-2599.

[167] B. Apostolovic, S.P. Deacon, R. Duncan, H.A. Klok, Hybrid polymer therapeutics incorporating bioresponsive, coiled coil peptide linkers. Biomacromolecules 11 (2010) 1187-1195.

[168] B. Apostolovic, S.P. Deacon, R. Duncan, H.A. Klok, Cell uptake and trafficking behavior of non-covalent, coiled-coil based polymer-drug conjugates. Macromol. Rapid Commun. 32 (2011) 11-18.

[169] W.A. Petka, J.L.Harden, K.P. McGrath, D. Wirtz, D.A. Tirrell, Reversible hydrogels from self-assembling artificial proteins. Science 281 (1998) 389-392.

[170] W. Shen, K. Zhang, J.A. Kornfield, D.A. Tirrell, Tuning the erosion rate of artificial protein hydrogels through control of network topology. Nat. Mater. 5 (2006) 153158.

[171] R. Langer, D.A. Tirrell, Designing materials for medicine and biology. Nature 428 (2004) 487-492.

[172] C. Xu, V. Breedveld, J. Kopeček, Reversible hydrogels from self-assembling genetically engineered protein block copolymers. Biomacromolecules 6 (2005) 1739-1749.

[173] P.L. Iversen, Phosphorodiamidate morpholino oligomers: favorable properties for sequence-specific gene inactivation. Curr. Opin. Mol. Ther. 3 (2001) 235-238.

[174] A. Amantana, P.L. Iversen, Pharmacokinetics and biodistribution of phosphorodiamidate morpholino antisense oligomers. Curr. Opin. Pharmacol. 5 (2005) 550-555.

[175] J. Summerton, D. Weller, Morpholino antisense oligomers: design, preparation, and properties. Antisense Nucleic Acid Drug Dev. 7 (1997) 187-195.

[176] Chemical \& Engineering News: Online: January 7, 2014; http://cen.acs.org/articles/92/web/2014/01/Nanoconjugates-Trigger-Cancer-CellSuicide.html]

[177] T.-W. Chu, R. Zhang, J. Yang, M.P. Chao, P.J. Shami, J. Kopeček, A two-step pretargeted nanotherapy for CD20 crosslinking may achieve superior antilymphoma efficacy to rituximab. Theranostics 5 (2015) 834-846.

[178] M.-A. Ghetie, H. Bright, E.S. Vitetta, Homodimers but not monomers of Rituxan (chimeric anti-CD20) induce apoptosis in human B-lymphoma cells and synergize with a chemotherapeutic agent and an immunotoxin. Blood 97 (2001) 1392-1398.

[179] R.N. Johnson, P. Kopečková, J. Kopeček, Synthesis and evaluation of multivalent branched HPMA copolymer-Fab' conjugates targeted to the B-cell antigen CD20. Bioconjug. Chem. 20 (2009) 129-137.

[180] R. N. Johnson, P. Kopečková, J. Kopeček, Biological activity of anti-CD20 multivalent HPMA copolymer-Fab' conjugates. Biomacromolecules 13 (2012) 727-735. 
[181] T.-W. Chu, J. Yang, J. Kopeček, Anti-CD20 multivalent HPMA copolymer-Fab' conjugates for the direct induction of apoptosis. Biomaterials 33 (2012) 7174-7181.

[182] S.R. Aluri, P. Shi, J.A. Gustafson, W.Wang, Y.A. Lin, H.Cui, S. Liu, P.S. Conti, Z. Li, P. Hu, A.L. Epstein, J.A. MacKay, A hybrid-protein - polymer nanoworm potentiates apoptosis better than a monoclonal antibody. ACS Nano 8 (2014) 2064-2076.

[183] N. Zhang, L.A. Khawli, P. Hu, A.L. Epstein, Generation of rituximab polymer may cause hyper-crosslinking induced apoptosis in non-Hodgkin's lymphomas. Clin. Cancer Res. 11 (2005) 5971-5980.

[184] T-W. Chu, K.M. Kosak, P.J. Shami, J. Kopeček, Drug-free macromolecular therapeutics induce apoptosis of patient chronic lymphocytic leukemia cells. Drug Deliv. Translational Res. 4 (2014) 389-394.

[185] G. Méhes, Chromosome abnormalities with prognostic impact in B-cell chronic lymphocytic leukemia. Pathol. Oncol. Res. 11 (2005) 205-210.

[186] L.E. van der Kolk, L.M. Evers, C. Omene, S. Lederman, R.A. van Lier, M.H. van Oers, E. Eldering, CD20-induced B cell death can bypass mitochondria and caspase activation. Leukemia 16 (2002) 1735-1744.

[187] J.C. Byrd, J.J. Jones, J.A. Woyach, A.J. Johnson, J.M. Flynn, Entering the era of targeted therapy for chronic lymphocytic leukemia: impact on the practicing clinician. J. Clin. Oncol. 32 (2014) 3039-3047.

[188] Y. Yazici, Rheumatoid arthritis: When should we use rituximab to treat RA? Nat. Rev. Rheumatol. 7 (2011) 379-380.

[189] V.S.-F. Chan, H.H.-L. Tsang, R.C.-Y. Tam, L. Lu, C.-S. Lau, B-cell-targeted therapies in systemic lupus erythematosus. Cell. Mol. Immunol. 10 (2013) 133-142.

[190] Z. Gu, J. Yamashiro, E. Kono, R.E. Reiter, Anti-prostate stem cell antigen monoclonal antibody $1 \mathrm{G} 8$ induces cell death in vitro and inhibits tumor growth in vivo via a Fc-independent mechanism. Cancer Res. 65 (2005) 9495-9500.

[191] M.H. Cho, E.J. Lee, M. Son, J.H. Lee, D. Yoo, J.W. Kim, S.W. Park, J.S. Shin, J. Cheon, A magnetic switch for the control of cell death signalling in in vitro and in vivo systems. Nat. Mater. 11 (2012) 1038-1043. 


\section{Captions}

Figure 1. The use of HEMA-based hydrogels (copolymers of HEMA with EDMA) in rhinoplasty. A) Patient before surgery; B) Patient after surgery. Reprinted from reference 33 with permission.

Figure 2. Tumor growth inhibition by P-CYP, P-DTX, and combination of P-DTX and PCYP in PC-3 tumor-bearing nude mice. Data are presented as mean $\pm S D$. Reprinted from reference 92 with permission.

Figure 3. Combination treatment of $2^{\text {nd }}$ generation conjugates showed improved therapeutic efficacy in A2780 human ovarian carcinoma xenografts. (A) Blood activity-time profiles of ${ }^{125}$ I-labeled conjugates in mice. The data represent the mean radioactivity expressed as a percentage of the injected dose per gram of blood from mice $(n=5)$. (B) SPECT/CT images of mice bearing subcutaneous A2780 human ovarian carcinoma in right flank after intravenous injection of 125 I-labeled conjugates (2P-PTX, 2P-GEM). The representative images were acquired $24 \mathrm{~h}, 48 \mathrm{~h}$, and $7 \mathrm{~d}$ after administration of conjugates. T, tumor. (C) Experimental schedules of treatment in mice bearing A2780 human ovarian tumor xenografts. Female nude mice received one dose of PTX or HPMA copolymer-PTX conjugate $(20 \mathrm{mg} / \mathrm{kg} \mathrm{PTX}$ equivalent) on day 0 and 3 doses of GEM or HPMA copolymer-GEM conjugate (5 mg/kg GEM equivalent) on days 1, 7, and 14. (D) A2780 tumor growth in mice treated with different formulation combinations $(n=5)$. ${ }^{*} p<0.01$. Note: in the orange (2P-PTX $\rightarrow 2 \mathrm{P}-\mathrm{GEM})$ line the error bars are hidden within the experimental points. (E) Photographs of A2780 tumors after treatment with different combinations. Reprinted from reference 87 with permission.

Figure 4. Percentage of bone mineral density increase in OVX Sprague-Dawley rats following administration of Asp $_{8}$-targeted HPMA copolymer-PGE 1 conjugates. The BMD was measured on day -2 and day 33. Left columns - untreated controls (saline); middle columns - P-Asp ${ }_{8} \mathrm{PGE}_{1}$ (1 $1^{\text {st }}$ generation conjugate, $\mathrm{Mw} 51.2 \mathrm{kDa})$; right columns - $\mathrm{mP}-\mathrm{Asp}_{8}-\mathrm{PGE}_{1}\left(2^{\text {nd }}\right.$ generation multiblock backbone degradable conjugate, Mw $329 \mathrm{kDa}$ ). ${ }^{*} P<0.05$ for $\mathrm{mP}-\mathrm{Asp}_{8}-\mathrm{PGE}_{1}$ group compared to control. ${ }^{\star \star} P<0.05$ for $\mathrm{mP}-\mathrm{Asp}_{8}-\mathrm{PGE}_{1}$ group compared to P-Asp $8-\mathrm{PGE}_{1}$ and control. $n=5$ per group. Data are means $\pm \mathrm{SD}$. Reprinted from reference 124 with permission.

Figure 5. A) The structure of the HPMA copolymer - 9-AC conjugate (P-9-AC). B) Survival curves of mice bearing human colon carcinoma xenografts treated by $9-A C$ and $P-9-A C$ at a dose of $3 \mathrm{mg} / \mathrm{kg}$ of $9-A C$ or $9-A C$ equivalent. Reprinted from reference 129 with permission.

Figure 6. Therapeutic efficacy of drug-free macromolecular therapeutics based on coiled-coil peptides against systemically disseminated Raji B cell lymphoma in C.B.-17 SCID mice (7 mice per group). A) Top panel shows timeline for the in vivo efficacy study. Four million Raji B cells were injected into the tail vein on day 0 to initiate the disseminated disease. The incidence of hind-limb paralysis or survival of mice was monitored until day 100. Five groups of animals were evaluated: untreated controls; consecutive administration of single dose (CS); premixed administration of single dose (PS); consecutive 
administration of three doses at days 1,3 , and 5 (CM); and premixed administration of three doses at days 1,3 , and 5 (PM). Consecutive administration involved the i.v. injection of $50 \mu \mathrm{g} / 20 \mathrm{~g}$ Fab'-CCE first and $1 \mathrm{~h}$ later the i.v. administration of $324 \mu \mathrm{g} / 20 \mathrm{~g}$ CCK-P conjugate; for premixed administration, the two conjugates were mixed together $1 \mathrm{~h}$ before injection via the tail vein. Bottom panel shows survival rate of tumor-bearing mice that received above treatments. The curve was presented in a Kaplan-Meier plot with indication of numbers of long-term survivors (7 mice per group); B) Estimation of residual Raji B lymphoma cells in the bone marrow. Shown are results from representative mice that received the indicated treatment. Revealed are histograms of bone marrow cells isolated from mice (as indicated) followed by staining with PE mouse anti-human CD10 and APC mouse anti-human CD19. Reprinted from reference 11 with permission.

Figure 7. In vivo efficacy of drug-free macromolecular therapeutics based on morpholino oligonucleotides against systemic B-cell lymphoma. SCID mice were injected with luciferase-expressing Raji cells $\left(4 \times 10^{6}\right)$ via the tail vein on day 0 . Three doses of each treatment were administered on days 7,9 , and 11. PBS: mice injected with PBS $(n=6)$; Cons $1 h$ : consecutive treatment of Fab'-MORF1 and P-MORF2, $1 \mathrm{~h}$ interval $(n=7)$; Cons $5 h$ : consecutive treatment of Fab'-MORF1 and P-MORF2, $5 \mathrm{~h}$ interval $(n=6)$; Rituximab $(n=$ $6)$; 1F5 mAb $(n=6)$. (A) Paralysis-free survival of mice presented in a Kaplan-Meier plot. Numbers of long-term survivors in each group are indicated. Statistics was performed with log-rank test $\left(*: p<0.05,{ }^{*}: p<\right.$ 0.005 , n.s.: no significant difference). (B) In vivo bioluminescence images at 25 days post-tumor injection. Mice were i.p. injected with $3 \mathrm{mg}$ firefly Dluciferin 15 min prior imaging. (C) Whole-body bioluminescence intensity of mice. Data are shown as mean \pm SEM ( $n=6$ or 7 ). Statistics was performed by student's $t$ test (**: $p<0.005)$. Black arrow: dose administration. Reprinted from reference 177 with permission. 
Figure 1

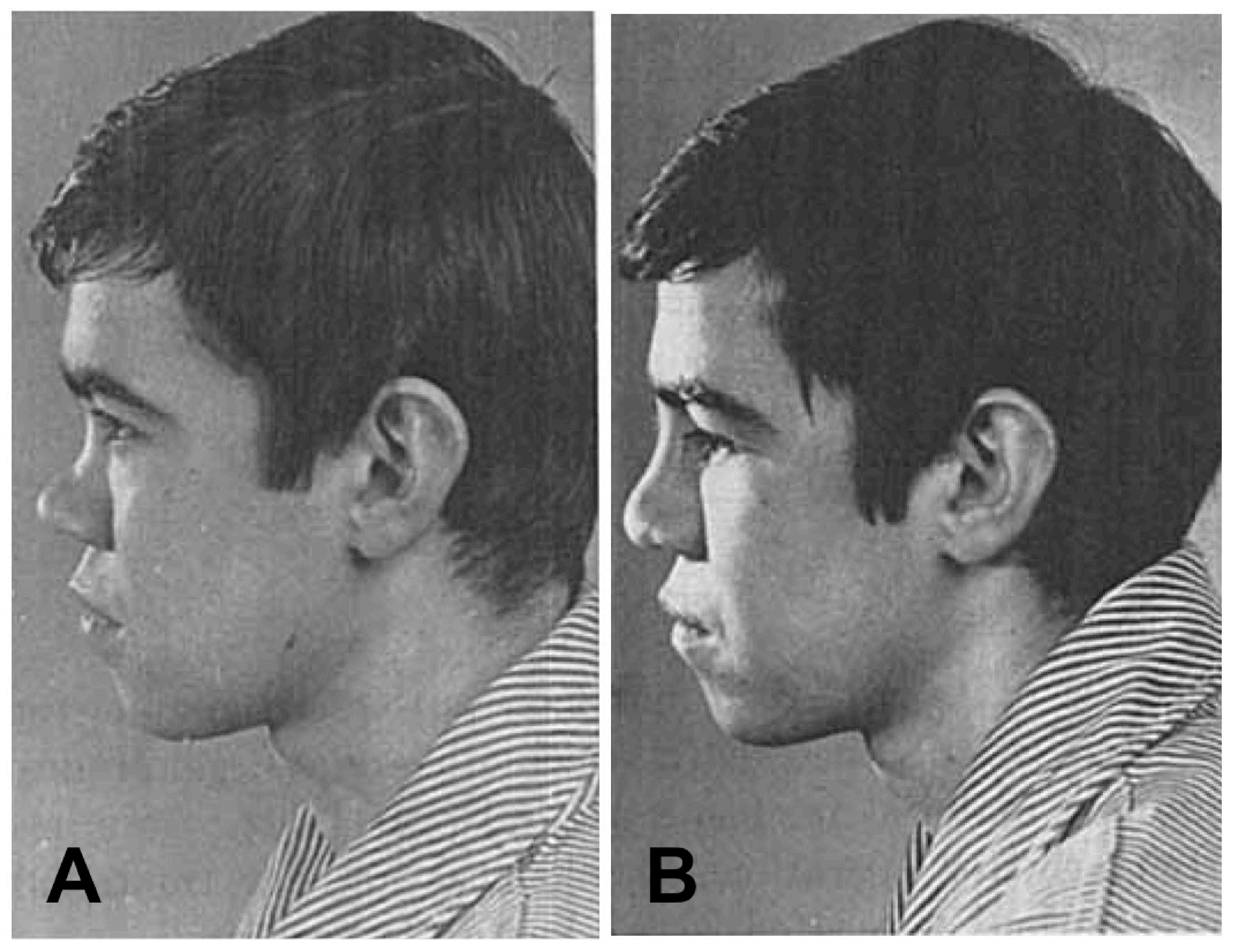


Figure 2

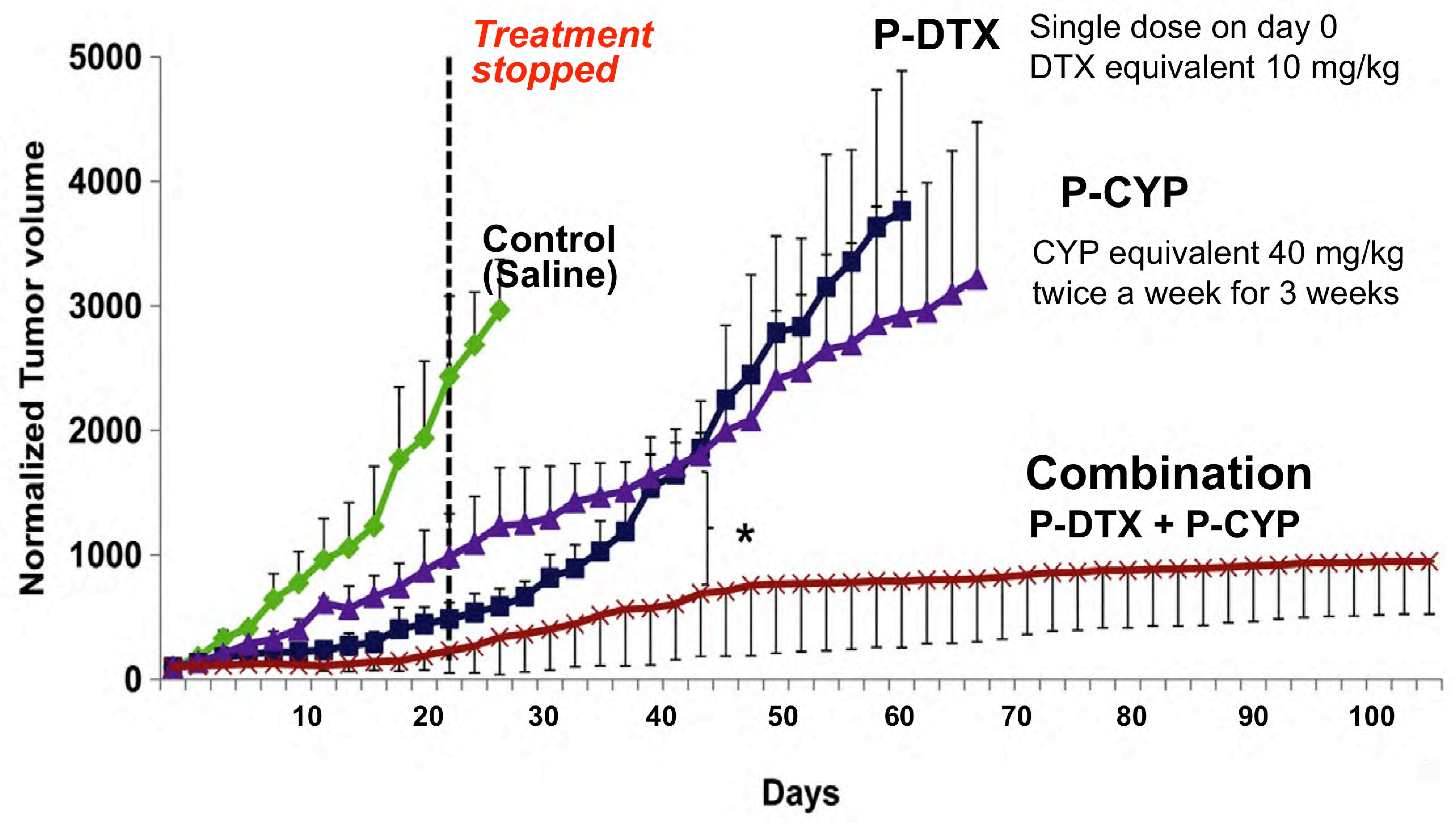


Figure 3

A Treatment Schedule:

Sequential combination treatment (a 21-day cycle) was given through i.v. injection.

i. $\quad$ PTX $\rightarrow$ GEM

ii. P-PTX $\rightarrow$ P-GEM

iii. 2P-PTX $\rightarrow$ 2P-GEM

iv. Control (saline)

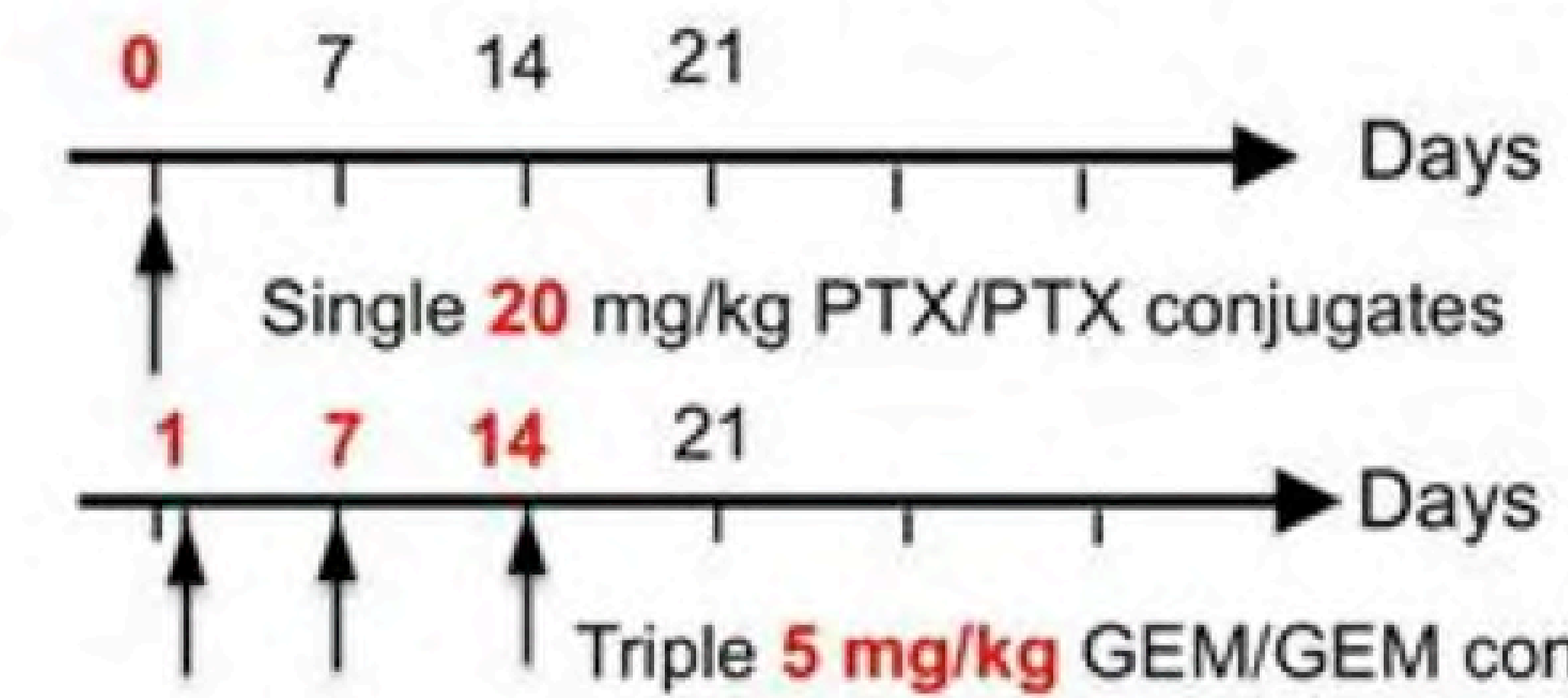

B

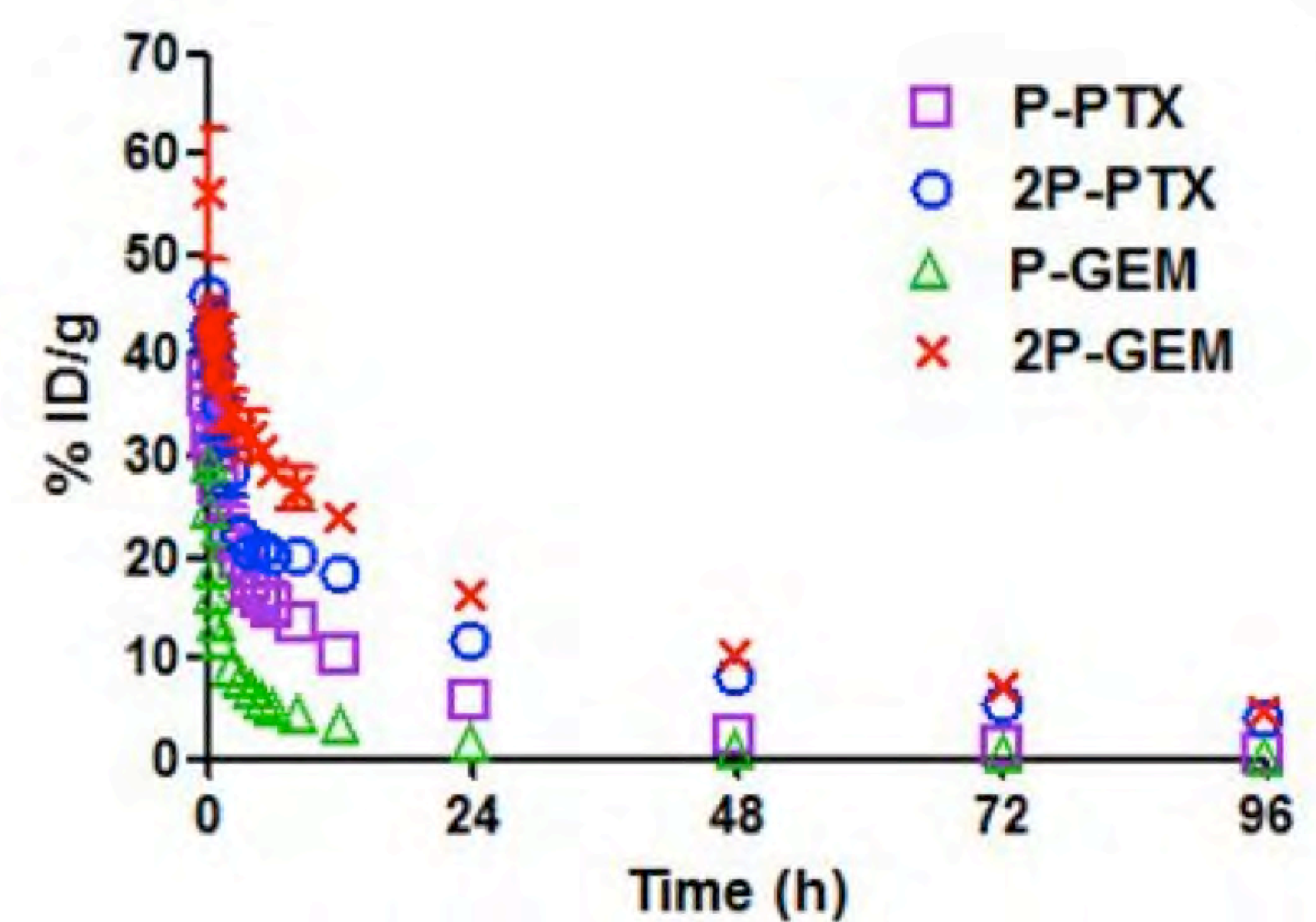

C

D

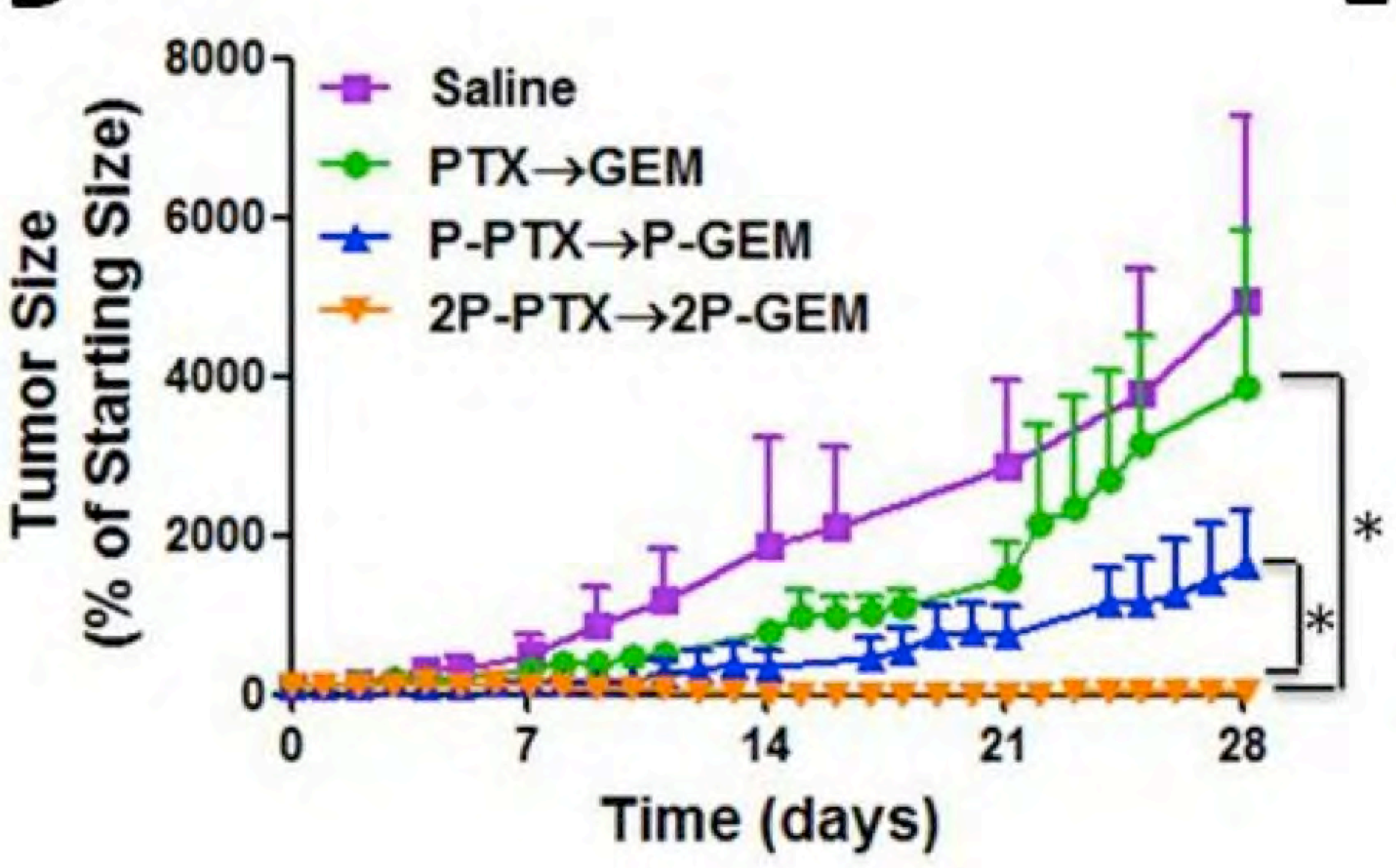

E

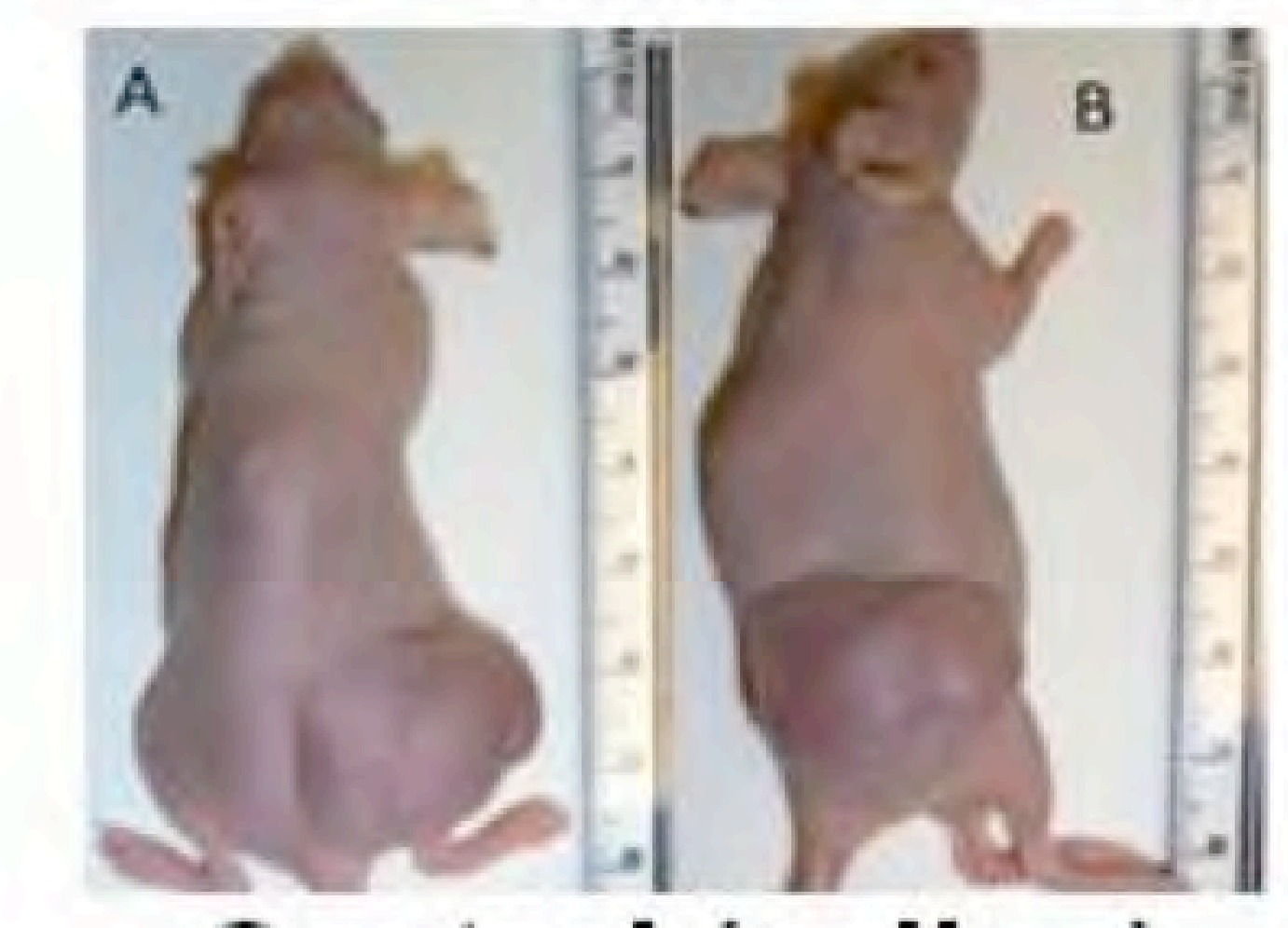

Control (saline)

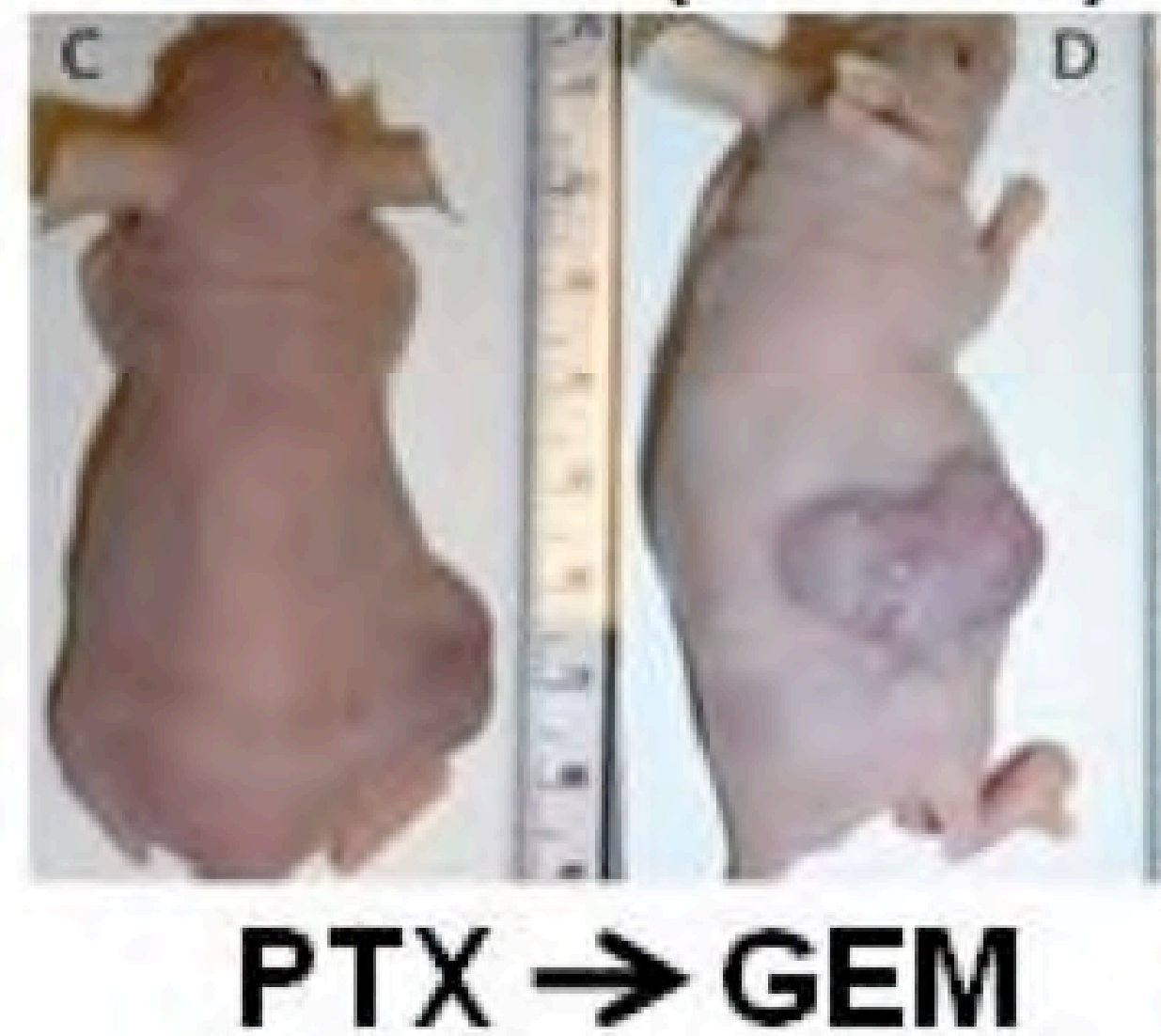

P-PTX $\rightarrow$ P-GEM

PTX $\rightarrow$ GEM

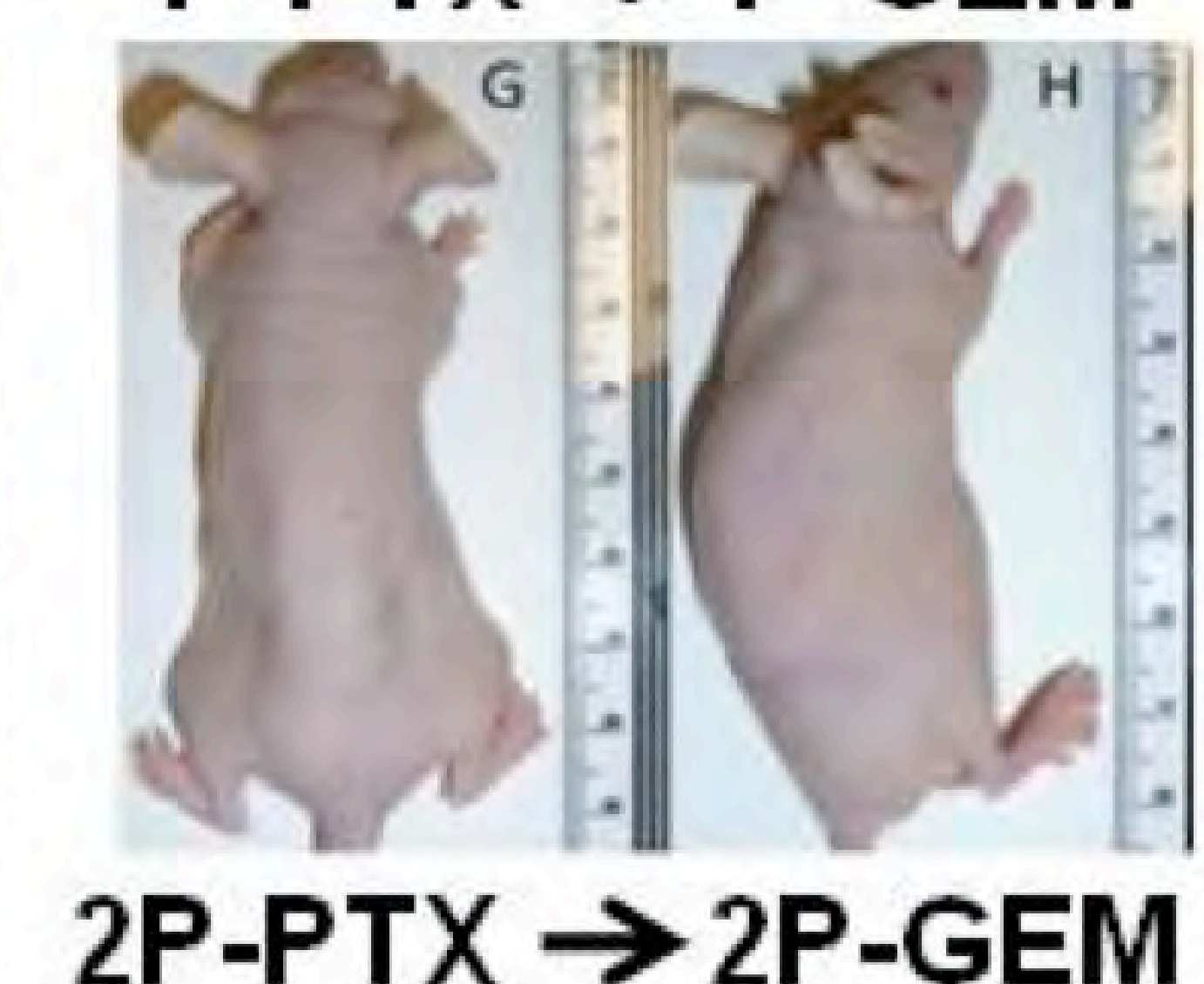


Figure 4

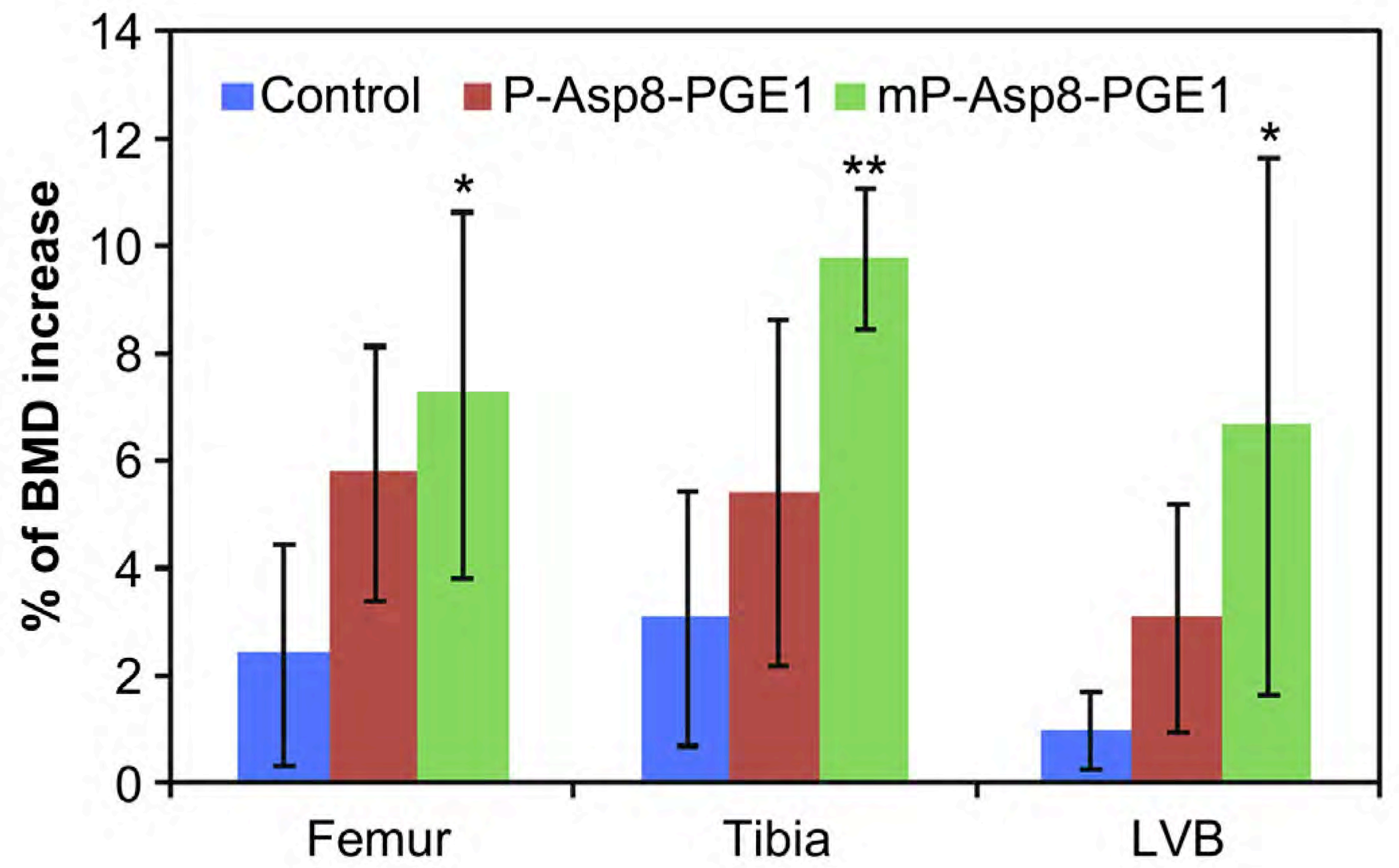




\section{Figure 5}
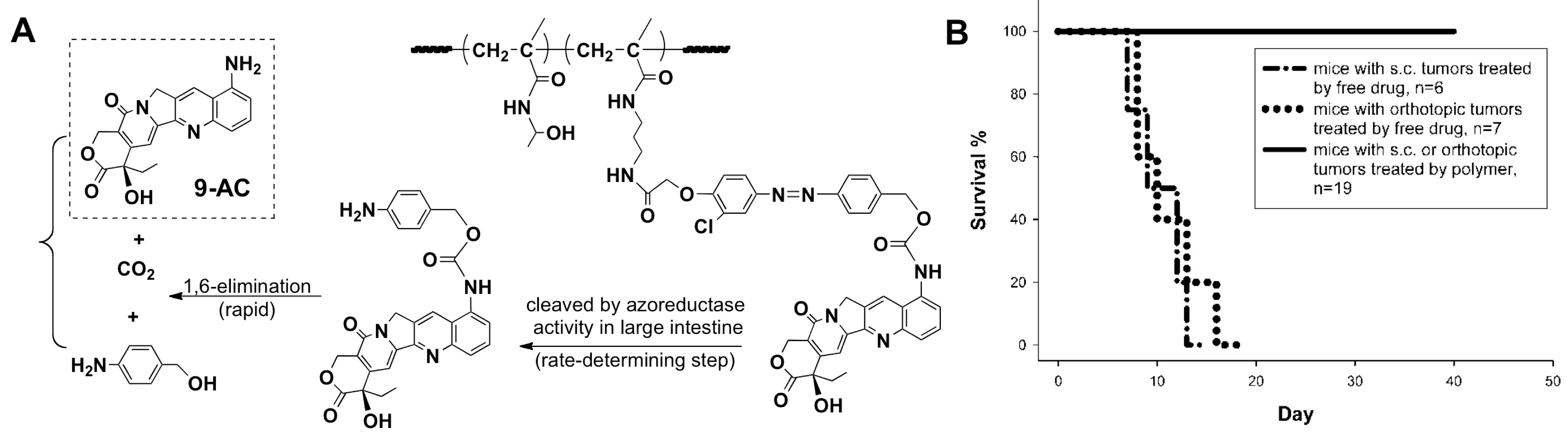


\section{Figure 6}

A Treatment with peptide-conjugates ( $P S, C S, P M$, and $C M$ )
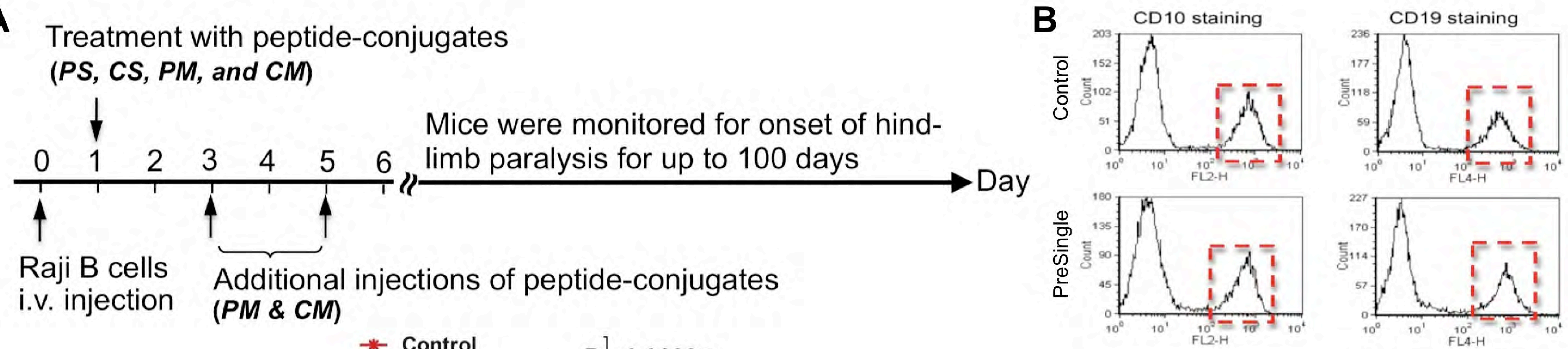

Raji B cells

Additional injections of peptide-conjugates i.v. injection

\section{(PM \& CM)}
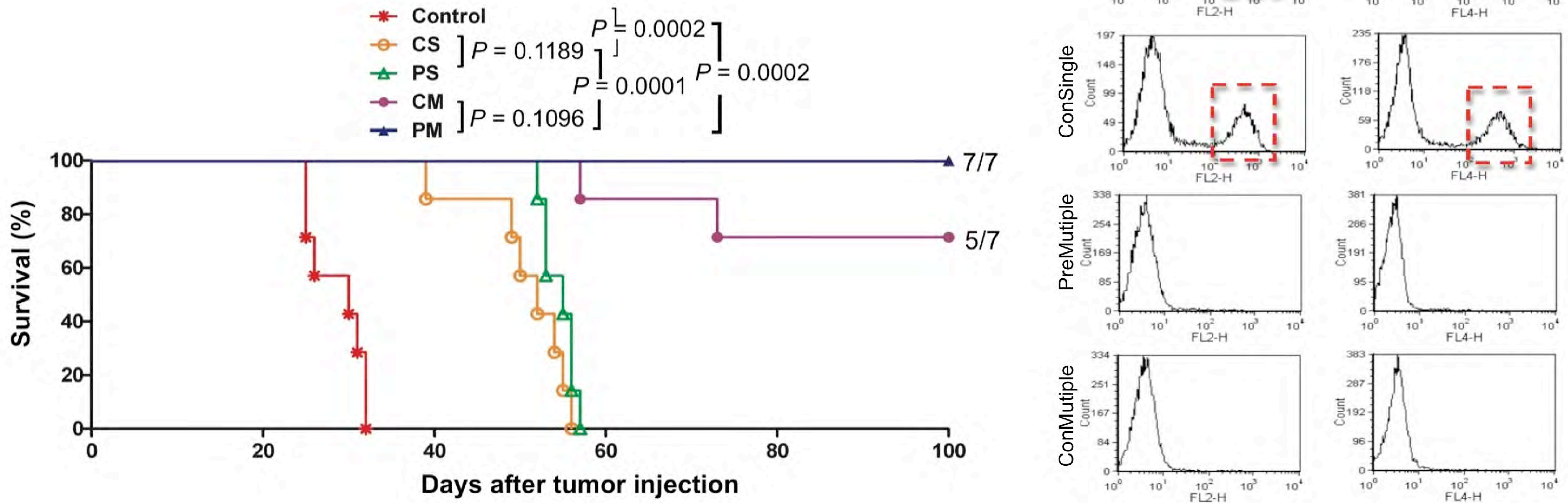
Figure 7
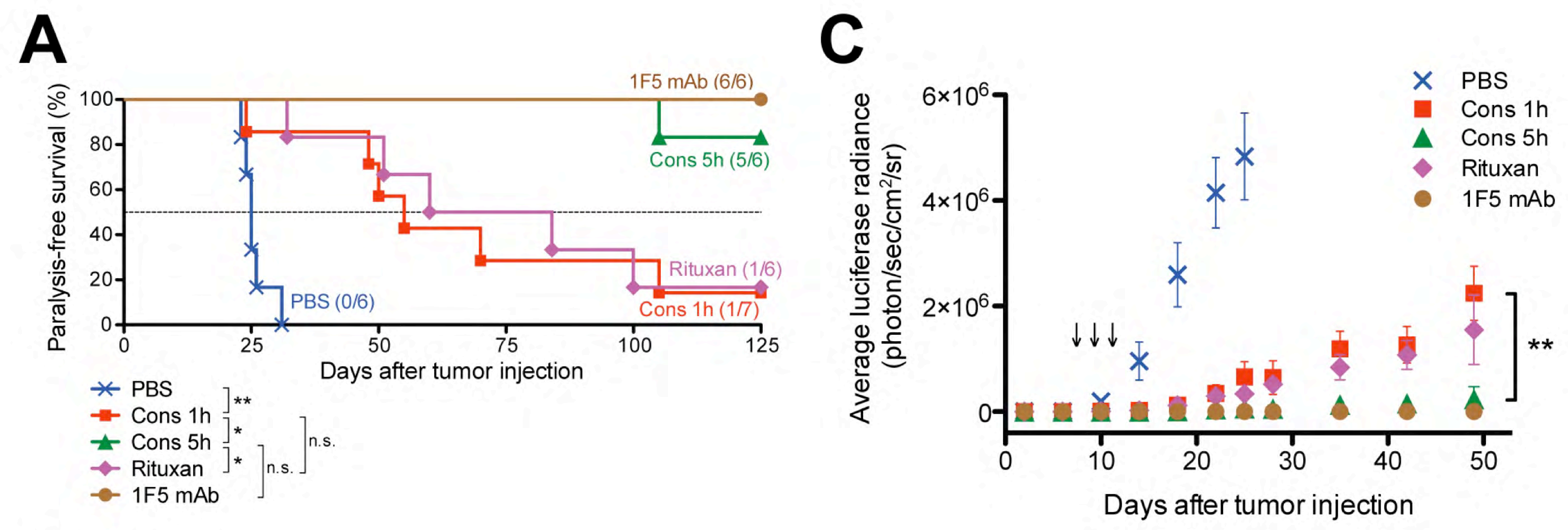

B
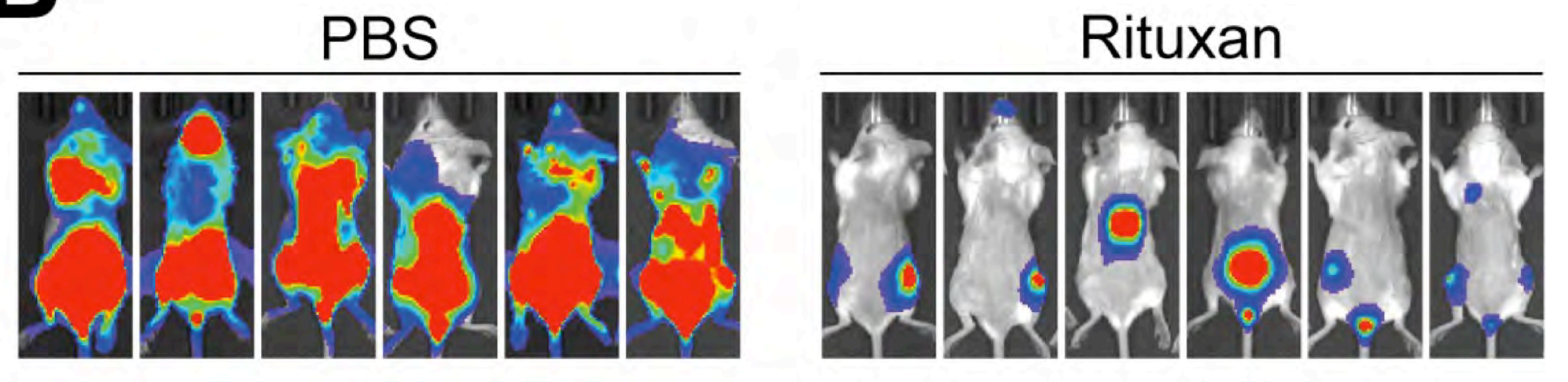

Cons $1 \mathrm{~h}$
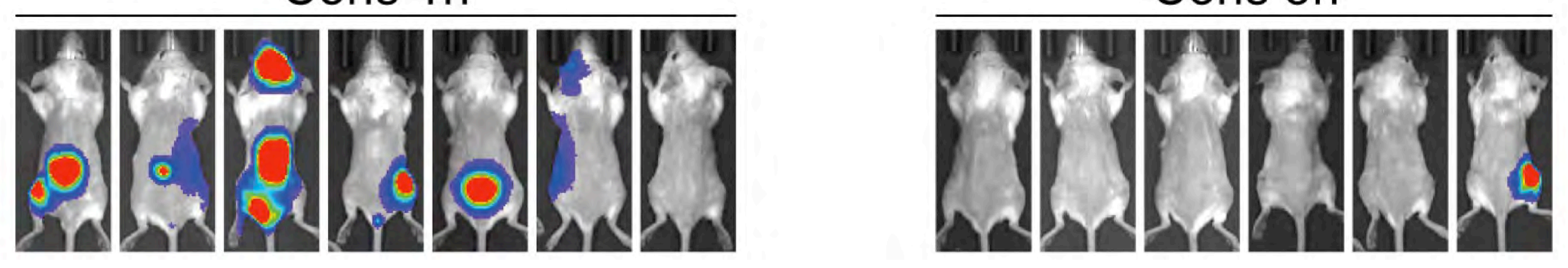
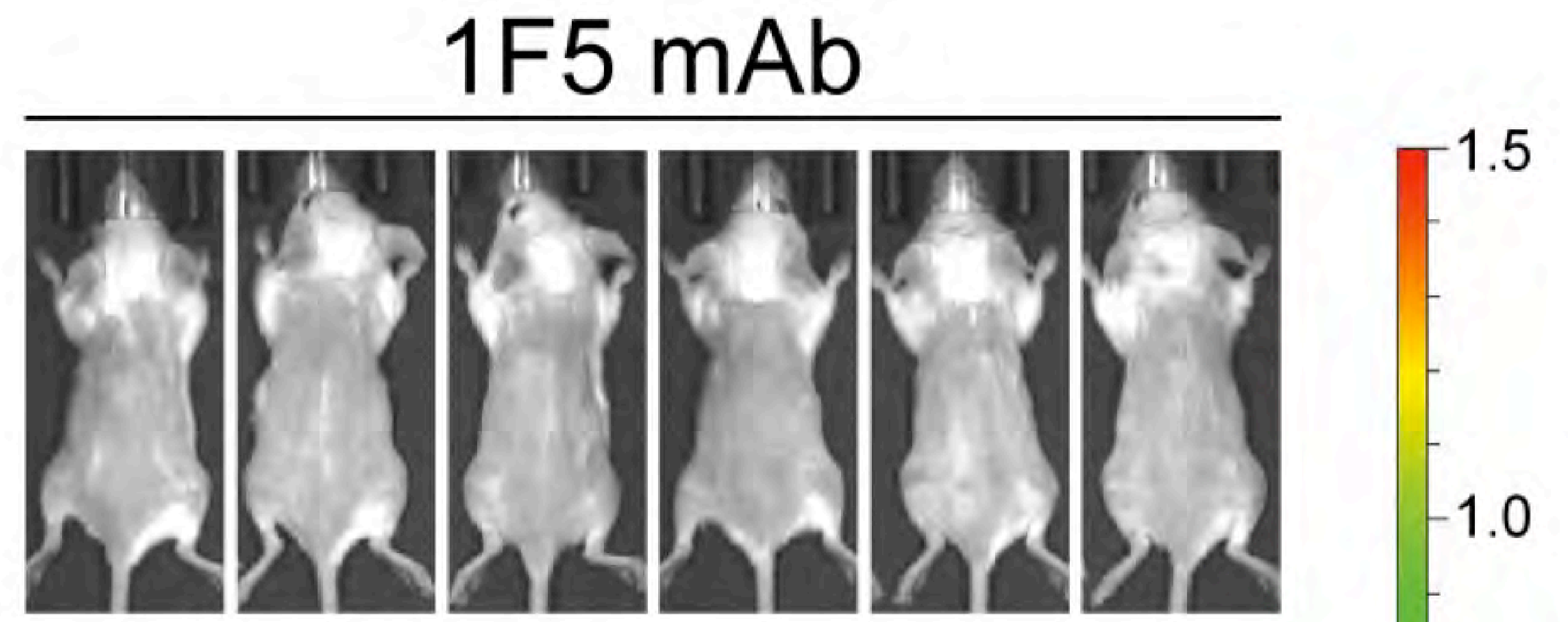

$\times 10^{7}$

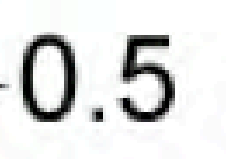

(photon $/ \mathrm{sec} / \mathrm{cm}^{2} / \mathrm{sr}$ ) 


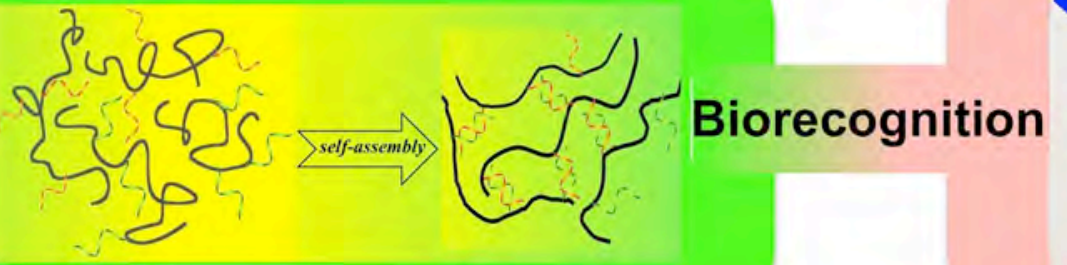

Smart biomaterials

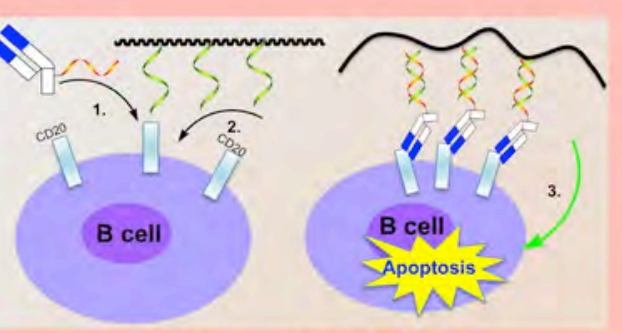

Nanomedicines 